NBER WORKING PAPER SERIES

\title{
FINANCIAL INTERMEDIARIES AND THE MACROECONOMY: EVIDENCE FROM A HIGH-FREQUENCY IDENTIFICATION
}

\author{
Pablo Ottonello \\ Wenting Song \\ Working Paper 29638 \\ http://www.nber.org/papers/w29638
NATIONAL BUREAU OF ECONOMIC RESEARCH
1050 Massachusetts Avenue
Cambridge, MA 02138
January 2022

Ottonello (pottonel@umich.edu): University of Michigan, Department of Economics and NBER. Song (wsong@bank-banque-canada.ca): Bank of Canada. We thank Simon Gilchrist, Juan Herreño, John Leahy, Jesse Schreger, and participants at various seminars and conferences for useful comments and suggestions. Caitlin Hegarty and Hanna Onyshchenko provided excellent research assistance. The views expressed herein are those of the authors and not necessarily those of the Bank of Canada or the National Bureau of Economic Research.

NBER working papers are circulated for discussion and comment purposes. They have not been peer-reviewed or been subject to the review by the NBER Board of Directors that accompanies official NBER publications.

(C) 2022 by Pablo Ottonello and Wenting Song. All rights reserved. Short sections of text, not to exceed two paragraphs, may be quoted without explicit permission provided that full credit, including $(\odot$ notice, is given to the source. 
Financial Intermediaries and the Macroeconomy: Evidence from a High-Frequency Identification Pablo Ottonello and Wenting Song

NBER Working Paper No. 29638

January 2022

JEL No. E30,E5,G01,G2

\begin{abstract}
$\underline{\text { ABSTRACT }}$
We provide empirical evidence of the causal effects of changes in financial intermediaries' net worth in the aggregate economy. Our strategy identifies financial shocks as high-frequency changes in the market value of intermediaries' net worth in a narrow window around their earnings announcements, based on U.S. tick-by-tick data. Using these shocks, we estimate that news of a 1-percent decline in intermediaries' net worth leads to a 0.2-0.4 percent decrease in the market value of nonfinancial firms. These effects are more pronounced for firms with high default risk and low liquidity and when the aggregate net worth of intermediaries is low.
\end{abstract}

\author{
Pablo Ottonello \\ Department of Economics \\ University of Michigan \\ 611 Tappan Street \\ Ann Arbor, MI 48109 \\ and NBER \\ pottonel@umich.edu \\ Wenting Song \\ Bank of Canada \\ wsong@bank-banque-canada.ca
}




\section{Introduction}

What effect do financial intermediaries have on the macroeconomy? This question, which has been central to macroeconomics since at least the Great Depression, has received significant attention from researchers in recent decades (see, for example, Bernanke, 1983; Reinhart and Rogoff, 2009a; Gertler and Gilchrist, 2018). The main empirical challenge in measuring the aggregate effects of intermediaries is that macroeconomic conditions that originate outside the financial system affect the balance sheets of intermediaries, which makes it difficult to isolate their aggregate effects on the economy.

In this paper, we propose a high-frequency (HF) identification strategy to study the causal effects of financial shocks on the aggregate economy. Our empirical strategy focuses on changes in individual financial intermediaries' net worth in a narrow window around their earnings announcements. In the spirit of the HF event-study approach to identify monetarypolicy shocks (surveyed by Nakamura and Steinsson, 2018a), our empirical strategy exploits the fact that earnings announcements are lumpy, which leads to a discontinuity in the content of financial news released around these events. Using these shocks, we document that declines in the market value of intermediaries' net worth leads to substantial effects on the market value of nonfinancial firms. These effects are more pronounced for firms with high default risk and low liquidity and when the aggregate net worth of the financial system is low.

Our paper begins by constructing a HF measure of financial shocks in the U.S. economy. Our measure of financial shocks uses tick-by-tick data on intermediaries' stock prices in 60minute windows around their earnings releases. We exploit the fact that publicly traded financial intermediaries have considerable market size, so idiosyncratic news about these intermediaries can have an effect on the total financial net worth, as in the recently proposed "granular" identification strategy (Gabaix and Koijen, 2020).

We then use HF financial shocks to study the effect of changes in intermediaries' net worth on nonfinancial firms. We provide evidence using two empirical strategies. One is an event-study approach, whose identifying assumption is that in a 60-minute window around intermediaries' earnings announcements, changes in the stock price of intermediaries that are releasing earnings are driven by information contained in these announcements. The other is a heteroskedasticity-based identification strategy (Rigobon, 2003; Rigobon and 
Sack, 2004; Hébert and Schreger, 2017), whose identifying assumption is that the variance of intermediaries' stock price during earnings-announcement events is larger than in nonevents, while that of nonfinancial firms is the same during event and nonevent dates. Using these two strategies, we document that a $1 \%$ change in intermediaries' net worth leads to a $0.2 \%$ to $0.4 \%$ percent change in the market value of nonfinancial firms in the S\&P 500. These effects are larger for small firms, as measured by returns of the S\&P SmallCap 600 and Russell 2000 indices; are robust to the frequency of analysis and weighting of the dependent variables; and affect firms' financing costs in bond markets as well as equity markets. In bond markets, financial shocks affect particularly the yields of high-risk bonds. For these bonds, we present additional within-firm-level evidence of the effects of financial shocks: Using security-level data on holdings by each financial institution, we show that within bonds issued by the same firm and with similar characteristics, those more heavily held by financial intermediaries that are reporting earnings exhibit a larger sensitivity to financial shocks.

Our empirical analysis also provides supportive evidence on the channels through which financial shocks affect nonfinancial firms. First, the effects we identify are governed by periods in which the aggregate net worth of the financial system is low, which suggests an important role for aggregate net worth channels (as stressed, for instance, by Gertler and Kiyotaki, 2010). Second, we show that firms more severely affected by financial frictions (e.g., higher credit risks and lower liquidity) are more severely affected by the financial shocks, which suggests that firms' financial positions matter in the aggregate transmission of these shocks (as highlighted, for example, in Khan and Thomas, 2013; Jermann and Quadrini, 2012; Christiano, Motto and Rostagno, 2014).

Our findings are consistent with a large body of empirical work that provides evidence that the net worth of financial intermediaries affects firms (e.g., Khwaja and Mian, 2008; Amiti and Weinstein, 2011; Chodorow-Reich, 2014; Huber, 2018) and asset prices (e.g., Coval and Stafford, 2007; Adrian, Etula and Muir, 2014; He, Kelly and Manela, 2017; Siriwardane, 2019, and He and Krishnamurthy, 2018 for a recent survey). An important element in the identification strategy developed in this body of work is the cross-sectional exposure of firms or assets to intermediaries. Our paper complements this literature by documenting intermediaries' aggregate effects. To date, empirical work on aggregate effects has used time-series methods (see, for example, Bernanke, 2018; Gertler and Gilchrist, 2018); a combination of 
cross-sectional and regional data (Gertler and Gilchrist, 2019); and model-based inference (see, for example, Christiano, Eichenbaum and Trabandt, 2015; Herreño, 2020). Our empirical analysis provides evidence on intermediaries in the aggregate economy, as well as on the role of aggregate intermediaries' net worth in shaping these effects, based on a HF identification strategy. We consider our method to be complementary to existing empirical work, with the advantage of $\mathrm{HF}$ methods in terms of requiring milder assumptions for the identification of aggregate effects (as discussed by Nakamura and Steinsson, 2018b, in the context of monetary policy shocks). ${ }^{1}$

\section{Data}

Our measure of financial shocks uses tick-by-tick data on intermediaries' stock prices in a window around their earning releases. We obtain tick-level stock prices from the New York Stock Exchange's Trade and Quote (TAQ). The TAQ database contains intraday trades timestamped to the second for all securities listed on the New York Stock Exchange, American Stock Exchange, Nasdaq, and SmallCap issues. We collect the earnings announcements' precise dates and times from the Institutional Brokers' Estimate System (IBES). Our baseline sample focuses on the commercial banks, investment banks, and securities dealers included in the S\&P 500 index during the period 1998 to $2014 .^{2}$ We focus on these types of intermediaries because their direct involvement in lending activities in the economy makes them more likely to be linked to the macroeconomy, which is our main focus of analysis. Table 1 details the set of 18 financial intermediaries selected using our main criteria, together with the period in which they are included in our analysis. Table 1 also shows that financial intermediaries in our sample represent $67 \%$ of the total equity of U.S. depository institutions, measured by the Federal Reserve's Flow of Funds. Therefore, our sample is based on large financial institutions, whose individual changes in net worth are likely to represent a significant change in the net worth of the entire financial sector. ${ }^{3}$ In our period of analysis,

\footnotetext{
${ }^{1}$ For additional work using the HF approach to study the effect of monetary policy shocks in the economy, see Cook and Hahn (1989); Kuttner (2001); Cochrane and Piazzesi (2002); Gürkaynak, Sack and Swanson (2004); Bernanke and Kuttner (2005); and Gorodnichenko and Weber (2016), among others.

${ }^{2}$ The financial intermediaries we use in the analysis correspond to NAICS 522110 and 523110, which are included in the S\&P 500 consecutively for at least 10 years to focus on a balanced sample, and we exclude regional banks (GICS 40101015) to focus on granular intermediaries.

${ }^{3}$ Gabaix and Koijen (2020) discuss how the idiosyncratic shocks to large players in the economy that affect aggregates constitute powerful instruments. Appendix A discusses the importance of granularity for
} 
Table 1: Financial Intermediaries Included in the Sample

\begin{tabular}{|c|c|c|c|c|c|c|}
\hline Financial Intermediary & Ticker & Start & End & $\begin{array}{l}\text { Avg Equity } \\
\text { (\$ billion })\end{array}$ & $\begin{array}{l}\text { Share of } \\
\text { Sample }\end{array}$ & $\begin{array}{c}\text { Share of } \\
\text { Aggr Equity }\end{array}$ \\
\hline Citicorp & CCI, C & 1998Q1 & 2014Q4 & 148.8 & $26.8 \%$ & $13.2 \%$ \\
\hline Bank of America & $\mathrm{BAC}$ & 1998Q1 & 2014Q4 & 136.4 & $24.6 \%$ & $12.1 \%$ \\
\hline Wells Fargo & WFC & 1998Q1 & 2014Q4 & 73.6 & $13.3 \%$ & $6.5 \%$ \\
\hline Goldman Sachs & GS & 2002Q3 & $2014 \mathrm{Q} 4$ & 51.7 & $6.8 \%$ & $3.9 \%$ \\
\hline Morgan Stanley & MWD, MS & 1998Q1 & 2014Q4 & 37.3 & $6.7 \%$ & $3.3 \%$ \\
\hline J.P. Morgan Chase & CMB, JPM & 1998Q1 & 2014Q4 & 36.0 & $1.1 \%$ & $6.3 \%$ \\
\hline Wachovia & WB & 1998Q1 & $2008 \mathrm{Q}^{a}$ & 35.8 & $4.2 \%$ & $4.0 \%$ \\
\hline Merrill Lynch & MER & 1998Q1 & 2008Q4 & 25.4 & $3.0 \%$ & $2.8 \%$ \\
\hline U.S. Bankcorp & USB & 1998Q1 & $2014 \mathrm{Q} 4$ & 22.1 & $4.0 \%$ & $2.0 \%$ \\
\hline Bank One & ONE & 1998Q1 & $2004 \mathrm{Q} 2^{b}$ & 19.8 & $1.3 \%$ & $3.0 \%$ \\
\hline Bank of New York Mellon & BK & 1998Q1 & 2014Q4 & 18.7 & $3.4 \%$ & $1.7 \%$ \\
\hline Fleet Boston Financial & FBF & 1998Q1 & $2004 \mathrm{Q} 1^{c}$ & 14.9 & $0.9 \%$ & $2.3 \%$ \\
\hline Lehman Brothers & LEH & 1998Q1 & 2008Q3 & 12.6 & $1.4 \%$ & $1.4 \%$ \\
\hline Ameriprise Financial & AMP & 2005Q4 & 2014Q4 & 8.6 & $0.8 \%$ & $0.6 \%$ \\
\hline First Chicago & FCN & 1998Q1 & $1998 \mathrm{Q} 4^{d}$ & 8.2 & $0.0 \%$ & $1.5 \%$ \\
\hline MNBA Corp & KRB & 1998Q1 & 2005Q4 & 7.6 & $0.6 \%$ & $1.0 \%$ \\
\hline Bankboston & BKB & 1998Q1 & $1999 \mathrm{Q} 3^{e}$ & 4.9 & $0.1 \%$ & $0.9 \%$ \\
\hline Northern Trust & NTRS & 1998Q1 & 2014Q4 & 4.6 & $0.8 \%$ & $0.4 \%$ \\
\hline Mean & & & & 37.1 & $5.56 \%$ & $3.71 \%$ \\
\hline $\mathrm{SD}$ & & & & 42.4 & $8.04 \%$ & $3.68 \%$ \\
\hline Min & & & & 4.6 & $0.04 \%$ & $0.41 \%$ \\
\hline Max & & & & 148.8 & $26.82 \%$ & $13.16 \%$ \\
\hline Total & & & & 667.0 & $100.00 \%$ & $66.82 \%$ \\
\hline
\end{tabular}

Notes: This table lists the financial intermediaries included in the sample and their tickers in TAQ. "Avg Equity" is the time series average of total shareholder equity of the financial intermediary. "Share of Sample" measures a financial intermediary's equity as a share of equity of all financial intermediaries in the sample. "Share of Aggr Equity" represents a financial intermediary's equity as a share of aggregate equity of U.S. depository institutions. ${ }^{a}$ Acquired by Wells Fargo. ${ }^{b}$ Merged with J.P. Morgan Chase. ${ }^{c}$ Acquired by Bank of America. ${ }^{d}$ Merged with Banc One to form Bank One. ${ }^{e}$ Merged with Fleet to form Fleet Boston.

we obtain 870 announcements of earnings, with roughly four per institution-year. Appendix Table B.1 provides detailed information on all earnings announcements by intermediaries contained in our sample.

We study the effects on nonfinancial firms using intraday stock prices of the S\&P 500 constituent securities, also obtained from the HF TAQ database. Our main analysis focuses on the movements of these nonfinancial constituents in a narrow window that matches that of financial shocks. We complement this analysis with additional daily indices data from FRED and Bloomberg - the S\&P 500 Ex-Financial, S\&P SmallCap 600, and Russell 2000 indices. Table B.2 presents descriptive statistics of daily stock returns in our period of analysis, identifying the effects of financial shocks in an illustrative theoretical framework. 
showing that days with financial shocks exhibit descriptive statistics similar to those of the whole period of analysis.

We also study the effect of financial shocks on the corporate bond market by using daily individual bond-level data from the constituents of the Intercontinental Exchange Bank of America's (ICE BofA) AAA and CCC and Lower U.S. Corporate indices. ${ }^{4}$ For each of these bonds, we have information on bond option-adjusted spread, together with various characteristics - index weightings, ratings, residual maturities, average trailing 30-day spreads, and month-to-date changes in spreads. The AAA index consists of 792 bonds and the CCC and Lower index consists of 3,937 bonds. Table B.3 presents descriptive statistics of the individual bond spread together with those for days with and without earning releases of financial intermediaries, which exhibit similar descriptive statistics.

To conduct additional analysis using within-firm-level variation, we gathered data on the share of bonds (at the cusip level) held by each reporting financial institution from Bloomberg. This information is available at quarterly frequency, so we collect data for each financial shock and for each outstanding bond in the quarter before the shock. To study the within-firm heterogeneous impacts of financial shocks, we restrict the sample of bonds to those rated CCC or lower issued by firms with at least 10 bonds outstanding. Table B.4 reports descriptive statistics of bond holdings. On average, the financial intermediaries in our sample represent 1,760 of the reported holdings of these bonds. These holdings exhibit heterogeneity, with a standard deviation of 11,337, which can be used to study the differential effects of bonds that are more or less strongly held by institutions releasing earnings reports.

\section{Measuring High-frequency Financial Shocks}

Construction of shocks We define HF financial shocks as changes in the stock price of the intermediaries reporting earnings in a narrow window around their earnings announcements:

$$
\varepsilon_{t}^{\mathrm{F}}=\sum_{i \in \mathcal{I}_{t}} \theta_{i, q(t)}\left(\log P_{i, \tau(i, t)+\Delta^{+}}-\log P_{i, \tau(i, t)-\Delta^{-}}\right),
$$

\footnotetext{
${ }^{4}$ The choice of daily frequency takes into account the less liquid nature of bond markets as well as the day-end settlement time of major participants (such as mutual funds).
} 
where $\mathcal{I}_{t}$ denotes the set of intermediaries reporting their announcement on day $t ; \tau(i, t)$ is the time of an announcement for institution $i$ in day $t$ (expressed in minutes within a day); $P_{i, \tau}$ is the stock price of institution $i$ in period $\tau ; \Delta^{+}$and $\Delta^{-}$control the size of the window around the announcement; and $\theta_{i, q(t)}$ is the market capitalization of institution $i$ as a share of the total market capitalization of institutions in our sample in the quarter before announcement day $q(t)$. For announcements made within trading hours, we select $\Delta(t)^{-}$to be 20 minutes before the announcement and $\Delta(t)^{+}$to be 40 minutes after the announcement, following Nakamura and Steinsson (2018b) for monetary-policy shocks. For announcements that occur after trading hours, we compute the financial shock as change between the closing and opening log prices. Given that our measure is more precise for announcements made within trading hours, we create two measures of financial shocks: a "narrow" measure that includes only this type of announcement and a "broad" one that includes both types of shocks. Appendix Figure B.1 illustrates our HF-identified shocks with four graphical examples. Panels (a) and (b) show two shocks that occur inside trading hours, with their magnitudes corresponding to median positive and negative shocks inside trading hours; Panels (c) and (d) illustrate shocks that occur outside of trading hours.

Table 2: Financial Shocks

\begin{tabular}{lccccc}
\hline & \multicolumn{2}{c}{ Changes in Stock Prices } & & \multicolumn{2}{c}{ HF Financial Shocks } \\
\cline { 2 - 3 } \cline { 5 - 6 } & $\begin{array}{c}\text { Reporting } \\
\text { Intermediaries }\end{array}$ & $\begin{array}{c}\text { All } \\
\text { Intermediaries }\end{array}$ & & $\begin{array}{c}\text { Reporting } \\
\text { Intermediaries }\end{array}$ & $\begin{array}{c}\text { All } \\
\text { Intermediaries }\end{array}$ \\
\hline Mean & -0.16 & -0.12 & & -0.03 & -0.03 \\
Median + & 1.22 & 4.64 & & 0.06 & 0.38 \\
Median - & -1.22 & -5.95 & & -0.08 & -0.42 \\
Std deviation & 2.68 & 12.43 & & 0.30 & 0.98 \\
5th percentile & -4.59 & -17.80 & & -0.56 & -1.51 \\
95th percentile & 3.81 & 20.76 & & 0.31 & 1.65 \\
\hline Observations & 343 & 343 & & 343 & 343 \\
\hline
\end{tabular}

Notes: This table shows descriptive statistics of the "narrow" measure of financial shocks, with earning releases inside of market trading hours, including pre-market and extended trading, if available. Changes in stock prices of the reporting financial intermediaries are constructed as described in the main text, and changes in stock prices of all intermediaries are the unweighted sum of all sample intermediaries' stock price changes around the reporting intermediaries' earning releases. HF financial shocks for reporting intermediaries are weighted by the market net worth of the financial intermediary as a fraction of the total market net worth of the sample in the quarter, and HF financial shocks for all intermediaries are the weighted sum based on all sample intermediaries. "Median +" and "Median -" refer to median positive and median negative shocks. 
Table 2 reports the descriptive statistics of the narrow measure of financial shocks. The first column shows the HF changes in log prices of reporting institutions around their earnings announcements. All statistics are displayed in percent. On average, the price changes of reporting institutions are close to zero, with a standard deviation of $2.7 \%$. Median positive and negative shocks are close to $1 \%$. The third column shows descriptive statistics of HF financial shocks - which, as shown in (1), weights each change in log price of reporting institutions by their market share. Weighting overall reduces the magnitude of the shocks, resulting in a standard deviation of $0.26 \%$ and median positive and negative shocks of $0.06 \%$ and $-0.05 \%$, respectively. In addition, we report changes in the financial sector around earnings announcements. The second column reports the unweighted sum of HF changes in log prices of all sample intermediaries included in the sample around an earnings announcement, and the fourth column reports the sum weighted by market share. Shocks based on all sample intermediaries are similarly centered around zero, and have amplified median positives and negatives and greater volatility compared with the baseline financial shocks.

Financial content of the shocks Appendix C conducts a set of exercises to examine the content of our measure of financial shocks. First, Appendix C.1 uses data on unexpected earnings in announcements to show that stock price movements from financial institutions tend to be positively associated with their surprise earnings, which suggests that financial shocks encode the information on earnings released in the announcements.

Second, Appendix C.2 conducts a set of textual analyses of news coverage of intermediaries' earnings announcements (from Wall Street Journal articles on intermediaries' earnings announcements). The textual sentiment of these news items is positively associated with surprised earnings and with HF shocks. Topics covered in the news articles revolve around intermediaries' idiosyncratic performance, most prominently in core business areas: loans, mortgages, and investment banking and trading. Narratives constructed in the reporting attribute stock price movements to earnings performance relative to forecasts and attribute earnings results to bank-specific factors, such as business mixes and loan outcomes. All evidence from textual analysis suggests that market participants attribute the changes in market values around earnings announcements to intermediaries' idiosyncratic factors.

The third exercise shows that financial shocks are not systematically linked to informa- 
tion available at the moment of earnings releases. For this, Appendix C.3 uses a state-of-theart machine-learning model and shows that HF financial shocks are not predictable based on existing macroeconomic or financial data available before the shocks, which suggests that financial shocks are not driven by information in the rest of the economy available before intermediaries' earnings have been released.

Fourth, Appendix C.4 reports the volatility of the stock price of financial intermediaries and nonfinancial firms during event windows with intermediaries' earnings announcements and compares it with the volatility during nonevent windows. These moments show that the volatility of financial intermediaries' stock prices during their earnings announcements increases by substantially more than those of nonfinancial firms during these events, which is consistent with the fact that intermediaries' earnings announcements contain more information about financial intermediaries than about nonfinancial firms. Based on this, in our empirical analysis in the next section we conduct a heteroskedasticity-based identification. This can be conducted even if common factors affect both intermediaries and nonfinancial firms during their earnings announcements, as long as the variance of intermediaries' stock price during earnings-announcement events is larger than on nonevent dates. In contrast, those of nonfinancial firms are the same during both event dates of earnings releases of financial intermediaries and nonevent dates.

\section{The Aggregate Effects of Financial Shocks}

Theoretical background We now use HF financial shocks to study the aggregate effects of financial intermediaries. Our empirical analysis is guided by theories that link the balance sheets of intermediaries to macroeconomic dynamics and asset prices (e.g., Gertler and Kiyotaki, 2010; He and Krishnamurthy, 2012, 2013; Brunnermeier and Sannikov, 2014; Maggiori, 2021, and references therein). In these models, a decline in the net worth of financial intermediaries (driven, for example, by a negative realization of returns on their investments) leads to contraction in the supply of funds for nonfinancial firms and a decline in nonfinancial firms' investment and market value. The strength of this effect is governed by the degree of financial frictions faced by intermediaries (see Appendix A and Morelli, Ottonello and Perez, 2021, among others). Therefore, analyzing the effects of financial shocks on the market value 
of nonfinancial firms can be informative regarding the degree of financial frictions faced by financial intermediaries, and ultimately of their macroeconomic role.

Event-time analysis Our main empirical strategy is an event-time study. The analysis is conducted at the constituent level for nonfinancial firms in the $\mathrm{S} \& \mathrm{P} 500$. We estimate the impact of financial shocks on the market value of nonfinancial firms by estimating

$$
\Delta y_{j t}=\alpha_{j}+\beta \varepsilon_{t}^{\mathrm{F}}+u_{j t}
$$

where the dependent variable, $\Delta y_{j t}$, is the HF log price change of nonfinancial stock $j$ in the 60 -minute window around a financial shock; $\varepsilon_{t}^{\mathrm{F}}$ is the narrow measure of the financial shock; $\alpha_{j}$ is a cusip fixed effect; and $u_{j t}$ is a random error term. The fixed effect absorbs unobserved effects from time-invariant stock characteristics. The coefficient of interest, $\beta$, measures the elasticity of the market value of nonfinancial firms to financial shocks. The identifying assumption we use to interpret these effects as causal is that in the 60-minute window around intermediaries' earnings announcements, changes in the stock price of intermediaries that release earnings are driven by information contained in these announcements and not by other factors that affect the stock prices of nonfinancial firms in an announcement-time window, contained in $u_{j t}$. We cluster standard errors two ways to account for correlation within stocks and within periods.

Table 3 reports the main results of estimating the aggregate effects of financial shocks. The baseline result in the first column of Panel (a) shows that a $1 \%$ change in the net worth of financial intermediaries leads to a $0.3 \%$ change in the net worth of nonfinancial firms. Controlling for business-cycle variables - output, employment, and a recession indicatoraffects neither the estimated elasticity nor the standard errors, as shown in the second column. ${ }^{5}$

Financial news released through the earnings announcements of these granular intermediaries can potentially influence the net worth of other intermediaries that have yet to report earnings; Appendix Figure B.2 shows that shocks to the market value of an earnings-

\footnotetext{
${ }^{5}$ To put these estimated coefficients into perspective, we note that during September of 2008 the market value of financial intermediaries contracted by $10 \%$ (or $\$ .14$ trillion) and that of nonfinancial firms in the S\&P 500 by $7.8 \%$ (or $\$ .62$ trillion). A back-of-the envelope calculation based on our empirical estimate would indicate that $38 \%$ of the contraction in the market value of nonfinancial firms during this period could be accounted for by the contraction of the market value in the net worth of financial intermediaries.
} 
Table 3: Effects of Financial Shocks on the Market Value of Nonfinancial Firms

(a) Event-Time

\begin{tabular}{lcccc}
\hline & $(1)$ & $(2)$ & $(3)$ & $(4)$ \\
& Releasing Intermediaries & \multicolumn{2}{c}{ All Intermediaries } \\
\hline Fin shock (narrow) & $0.291^{* *}$ & $0.292^{* *}$ & $0.183^{* * *}$ & $0.189^{* * *}$ \\
& $(0.140)$ & $(0.147)$ & $(0.061)$ & $(0.060)$ \\
& & & & \\
\hline Observations & 104,167 & 104,167 & 103,591 & 103,591 \\
$R^{2}$ & 0.014 & 0.015 & 0.032 & 0.034 \\
Macro controls & no & yes & no & yes \\
Cusip FE & yes & yes & yes & yes \\
Double-clustered SE & yes & yes & yes & yes \\
\hline
\end{tabular}

(b) Heteroskedasticity-Based

(5)

All Intermediaries

\begin{tabular}{lcc}
\hline Fin shock (narrow) & $0.360^{* * *}$ & $0.361^{* * *}$ \\
SE & $(0.028)$ & $(0.028)$ \\
95 percent CI & {$[0.296,0.412]$} & {$[0.295,0.412]$} \\
\hline Observations & 1,281 & 1,281 \\
Macro controls & no & yes \\
\hline
\end{tabular}

Notes: Panel (a) estimates variants of the event-time regression in (2): $\Delta y_{j t}=\alpha_{j}+\beta \varepsilon_{t}^{\mathrm{F}}+u_{j t}$ where $\Delta y_{j t}$ is the HF log price change of a nonfinancial S\&P 500 constituent stock $j ; \varepsilon_{t}^{\mathrm{F}}$ is the narrow measure of the HF financial shock; and $\alpha_{j}$ is a cusip fixed effect. Macro controls include output, employment, and an indicator variable for recession. Columns 3 and 4 replace $\varepsilon_{t}^{\mathrm{F}}$ with a HF shock constructed using the price changes of all sample intermediaries, as described in the main text, whose estimate is more comparable to heteroskedasticity-based estimates. Standard errors are two-way clustered at shock and cusip level and reported in parentheses. Panel (b) reports the heteroskedasticity-based estimator for $\beta$ from the bivariate model (3) implemented with an instrumental variable framework. First-stage F-statistics are 423 and 421 for columns 5 and 6 , respectively. Standard errors and confidence intervals are computed with stratefied bootstrap, as described in the text. ${ }^{*}(p<0.10),{ }^{* *}(p<0.05),{ }^{* * *}(p<0.01)$.

releasing intermediary leads to a $0.2 \%$ increase in the market value of other nonreleasing intermediaries. In the third and fourth columns of Panel (a), we account for these effects and alternatively measure the financial shock based on the price changes of all sample intermediaries (i.e., replacing $\mathcal{I}_{t}$ with $\mathcal{I}_{q}$ in the shock definition in Equation (1)). As with the baseline shocks, changes in financial net worth lead to changes in the net worth of nonfinancial firms. The estimated elasticity of 0.2 is slightly smaller than the baseline estimate, which reflects a smaller role of non-releasing intermediaries in the rest of the economy. 
Robustness and placebo tests In the appendix, we conduct a series of analyses to verify the robustness of the findings. First, the effects of financial shocks are robust to the weighting of the dependent variables. Appendix Table B.5 uses as the dependent variable S\&P 500 nonfinancial constituents' log changes in net worth weighted by their market values at the beginning of the quarter. The estimated impact, at 0.2 , is slightly smaller than the equal-weighted benchmark, which suggests that the financial shocks have a stronger effect on smaller firms. The table also reports the effect on the broad S\&P 500 index, measured through the exchange-traded fund SPDR at high frequency, similar to the baseline estimates in terms of both economic magnitude and statistical significance.

Second, these effects do not depend on the frequency of analysis or the set of nonfinancial firms. Appendix Table B.6a shows that the effects are amplified at daily frequency and that they not specific to firms included in the S\&P 500 index, but also influence additional indices; these include the S\&P SmallCap 600 and Russell 2000. The impact of financial shocks is larger for the smaller and riskier firms included in these indices, which leads us to further study the heterogeneous transmission in Section 5 .

Third, Appendix Table B.7 shows that the effects of financial shocks are robust and stronger if we instead use the broad measure of financial shocks, including announcements made outside of trading hours.

Fourth, financial shocks also have effects on the spreads of risky bonds. In Appendix Figure B.3, we study the effect on corporate bond spreads for different credit ratings with pooled Jordà (2005) local projections, using the data on individual bonds that form the ICE BofA's indices described in Section 2. Panel (a) shows that financial shocks have no substantial effects on the option-adjusted spreads of AAA-rated bonds. Panel (b) shows that financial shocks have a significant and persistent effect on the spreads of bonds rated CCC or worse. The magnitude of these effects indicates that a $1 \%$ decline in the market value of intermediaries' net worth leads to a $0.1-0.5$-percentage-point increase in spreads in the month following an event.

We also conduct two "placebo" exercises to provide further evidence for our interpretation of the event-time results. The first placebo exercise, shown in Appendix Figure B.4, demonstrates that the HF shocks do not have an effect on the market value of nonfinancial firms during the days before the shock, which suggests that the effects are not driven by 
pretrends. This figure also shows that the HF shocks do not have an impact on the days after the shocks, which suggests that the information in financial shocks is incorporated in the value of nonfinancial firms on the day of the shock and that there are no offsetting forces on consecutive days that revert the impact effects of these shocks.

The second set of exercises shows that the effects we identify for financial shocks are not found if we follow a similar procedure to identify shocks that origingate in nonfinancial firms. To conduct this exercise, we follow a HF procedure similar to that developed in Section 3 for financial shocks, but focus on the earnings announcements of nonfinancial firms included in the Dow Jones index. Appendix Table B.6b shows the results of estimating the event-time regression but using the shock to nonfinancial firms instead of the financial shock. Results indicate a baseline estimate that is negative, not statistically significant, and unstable across specifications (e.g., has a negative point estimate when we use the narrow version of the shocks but positive with a broad version of the shocks).

Furthermore, we construct HF placebo shocks for each of the 10 nonfinancial sectors in the S\&P 500. As in the procedure for financial shocks, we collect the precise dates and times for nonfinancial firms' earnings releases and compute their log price changes in a narrow 60-minute window around the announcement, weighted by their market values. We estimate $\Delta \log y_{t}^{-s}=\alpha+\beta \varepsilon_{t}^{s}+u_{s t}$ for each sector $s \in\{$ energy, materials, information technology, ... $\}$, where $\varepsilon_{t}^{s}$ is the placebo shock and $y_{t}^{-s}$ is the equity index that excludes the placebo shock sector. Appendix Table B.8 reports the estimates, all of which are statistically insignificant; this suggests that the effects we identify in our empirical model are specific to financial intermediaries.

Heteroskedasticity-based identification A potential concern about the event-time approach is that factors unrelated to the release of earnings of intermediaries may ultimately be related to the stock prices of nonfinancial firms, even within a narrow window around earnings announcements. We address this concern by conducting an alternative estimation based on a heteroskedasticity-based identification strategy (Rigobon, 2003; Rigobon and Sack, 2004). This strategy can be conducted even in the presence of common factors that affect the market values of both intermediaries and nonfinancial firms, as long as the variance of intermediaries' stock price during earnings-announcement event times is larger than in 
nonevent times, while those of nonfinancial firms are the same during both earning releases of financial intermediaries and nonevent times.

To conduct the estimation based on heteroskedasticity for the same 60-minute event window that matches the frequency from the event-time analysis, we consider the bivariate model

$$
\begin{aligned}
\Delta \nu_{t}^{\mathrm{F}} & =\alpha \Delta y_{t}+\Phi^{\prime} Z_{t}+e_{t} \\
\Delta y_{t} & =\beta \Delta \nu_{t}^{\mathrm{F}}+\Gamma^{\prime} Z_{t}+u_{t},
\end{aligned}
$$

where $\Delta \nu_{t}^{\mathrm{F}}$ is the log change in a value-weighted index of intermediaries' stock prices in the 60 -minute window around an earnings result announced at time $t ; \Delta y_{t}$ is the log change in a value-weighted index of nonfinancial firms' stock prices in the same window; and $Z_{t}$ is a vector of control variables. The coefficient of interest, $\beta$, estimates the impact of changes in financial net worth on nonfinancial net worth.

Unlike the event-time analysis estimating (2), the heteroskedasticity-based approach uses data from both the times in which intermediaries release their announcements and those in which they do not. We define events as the times in which the financial intermediaries in our sample report earnings and compare against nonevents, defined as the times in which nonfinancial firms in the S\&P 500 releases earnings. To isolate the effects of financial intermediaries, we exclude from the set of nonevents nonfinancial firms' earnings that are within 2 days of a financial earnings event.

We estimate the coefficient of interest, $\beta$, following the instrumental variable implementation developed by Rigobon and Sack (2004). Standard errors and confidence intervals use the bootstrap procedure developed by Hébert and Schreger (2017) to correct for small-sample bias. $^{6}$

Panel (b) of Table 3 shows the results from estimating the effects of financial shocks on nonfinancial firms using a heteroskedasticity-based approach. The elasticity is estimated to be 0.4 and statistically significant. To compare estimates between the event-time and heteroskedasticity-based approaches, we include in the third and fourth columns of Panel (a) the event-time regressions with financial shocks based on the price changes of all sample

\footnotetext{
${ }^{6}$ We use 1,000 repetitions of a stratified bootstrap, resampling with replacement from events and nonevents.
} 
intermediaries and not just the reporting intermediary. Full comparison between the two identification strategies, for different weightings and frequency, is reported in Appendix Table B.9. Although weaker assumptions are imposed, the effects of financial shocks identified through heteroskedasticity are stronger than the event-study estimates, which suggests that our baseline results based on event-time analysis provides a lower bound on the impact of financial shocks.

Within-firm variation Finally, another concern about our interpretation of results could be that they are driven by an "information channel": Intermediaries' earnings releases may reveal information on nonfinancial firms' prospects, and this information may be incorporated to nonfinancial firms' security prices following intermediaries' announcements. We show that our results are not driven by this information channel, by exploiting the variation in individual bond prices within a firm around financial shocks. The idea of this exercise is to compare the prices of bonds issued by the same firm and with similar characteristics but held by different financial intermediaries. ${ }^{7}$ In particular, we estimate the model

$$
\Delta z_{k(j) i t}=\alpha_{j}+\alpha_{s q}+\beta \varepsilon_{t}^{\mathrm{F}}+\gamma \theta_{k(j) i t} \varepsilon_{t}^{\mathrm{F}}+\Gamma^{\prime} Z_{j t}+u_{j i t}
$$

where $\Delta z_{k(j) i t}$ is the changes in bond option-adjusted spreads; ${ }^{8} \varepsilon_{t}^{\mathrm{F}}$ is the narrow HF financial shock around intermediary $i$ 's earnings announcement; $\theta_{k(j) i t}$ is the share of bond $k$ issued by firm $j$ held by intermediary $i$ ' in the quarter proceeding its earnings announcement in period $t ; \alpha_{j}$ is a firm fixed effect; $\alpha_{s q}$ is a sector-by-quarter fixed effect; and $Z_{j t}$ is a vector of bond controls that includes bond holdings $\theta_{k(j) i t}$, a categorical variable for bond ratings, remaining maturity, trailing average, and month-to-date changes in spreads. We estimate (4) by focusing on the subset of firms with more than 10 bonds outstanding-which allows us to exploit the within-firm variation in bonds' exposure to intermediaries - and on bonds rated CCC or worse - which, as shown above, are most exposed to financial shocks; this yields a sample of 172 bonds issued by 21 firms. Standard errors are double-clustered by

\footnotetext{
${ }^{7}$ This identification strategy is similar to that used in Morelli et al. (2021) for the sovereign-debt market.

${ }^{8}$ We measure spreads as the option-adjusted spread (used, for example, in Anderson and Cesa-Bianchi, 2020), defined as the amount by which the government spot curve is shifted to match the present value of discounted cash flows to the corporate bond's price, incorporates both a maturity adjustment (Gilchrist, Yankov and Zakrajšek, 2009), by computing the spread relative to a risk-free security of matching maturity, and an option adjustment (Duffee, 1998), by removing the price of the embedded option.
} 
shock and firm.

The coefficient of interest in (4) is $\gamma$, which measures how the semielasticity of a bond's spreads to a financial shock depends on the holdings by intermediaries releasing earnings reports during the shock. Under the hypothesis that the effects of financial shocks on nonfinancial firms are driven by an information channel, the coefficient $\gamma$ should not be different from zero, because bonds issued by the same firm and with similar characteristics should be similarly affected by the information. Panel (a) of Table 4 reports that the estimated coefficient for $\gamma$ is negative and statistically significant, which indicates that within a firm, bonds that have more substantial holdings by the intermediary releasing earnings have a larger sensitivity in absolute value to financial shocks. Moreover, the magnitude of the estimated coefficients of $\beta$ and $\gamma$ indicate that a bond that is fully held by financial intermediaries releasing earnings reports experiences a semielasticity that is four times the average effect. These results are consistent with financial shocks' having an effect on the security prices of nonfinancial firms through financial intermediaries' net worth, which under short-run trading frictions can translate into different prices for bonds with similar risk (see Morelli et al., 2021).

\section{Inspecting the Transmission Mechanism}

How do financial shocks transmit to the rest of the economy? This section provides supportive evidence that the transmission of financial shocks is linked to the aggregate conditions of the financial system and to nonfinancial firms' financial positions.

\subsection{Aggregate state dependency}

Empirical evidence on the role of financial intermediaries in the macroeconomy often comes from analyzing episodes of financial crises (Reinhart and Rogoff, 2009b; Chodorow-Reich, 2014; Huber, 2018). Motivated by this evidence, we begin by investigating the importance of aggregate conditions in the transmission of financial shocks. We decompose the effects of financial shocks on nonfinancial firms by estimating

$$
\Delta y_{j t}=\alpha_{j}+\beta_{w} \cdot \varepsilon_{t}^{\mathrm{F}} \mathbb{1}\left(\varepsilon_{t}^{\mathrm{F}}>\bar{\varepsilon}_{t}\right)+\beta_{u} \cdot \varepsilon_{t}^{\mathrm{F}} \mathbb{1}\left(\varepsilon_{t}^{\mathrm{F}}<\bar{\varepsilon}_{t}\right)+\Gamma^{\prime} Z_{t}+u_{j t}
$$


Table 4: Transmission Channels of Financial Shocks

$\begin{array}{cccccc}\begin{array}{c}\text { Average } \\ \text { Effect }\end{array} & \begin{array}{c}\text { Interation } \\ \text { Effect }\end{array} & \begin{array}{c}\text { Adj. } \\ R^{2}\end{array} & \text { Obs. } & \text { FE } & \begin{array}{c}\text { Double } \\ \text { Cl. SE }\end{array}\end{array}$

(a) Within-firm variation

dependent var.: CCC bonds

by bond holdings

$\begin{array}{lr}-0.079^{*} & -0.267^{* *} \\ (0.038) & (0.110)\end{array}$

0.121

9,637

sector-qtr,

yes

firm

(b) Aggregate state dependency

dependent var.: S\&P 500 constituents

$\begin{array}{lcccccr}\text { average } & 0.291^{* *} & & 0.009 & 104,167 & \text { cusip } & \text { yes } \\ & (0.140) & & & & & \\ \text { well capitalized } & & 0.098 & 0.015 & 104,167 & \text { cusip } & \text { yes } \\ & & (0.233) & & & & \\ \text { undercapitalized } & & & & \\ & & & & \end{array}$

(c) Heterogeneous responses by firms

dependent var.: S\&P 500 constituents

$\begin{array}{lccccccc}\text { high leverage } & 0.252^{* *} & 0.024 & 0.023 & 598,572 & \text { sector-qtr, } & \text { yes } \\ & (0.108) & (0.018) & & & \text { firm } & \\ \text { invt-grade credit ratings } & 0.330^{* *} & -0.075^{*} & 0.039 & 162,267 & \text { sector-qtr, } & \text { yes } \\ & (0.142) & (0.043) & & & \text { firm } & \\ & & & & & \\ & 0.283^{* *} & -0.038^{* *} & 0.023 & 598,530 & \text { sector-qtr, } & \text { yes } \\ \text { high liquidity } & (0.109) & (0.015) & & & \text { firm } & \end{array}$

Notes: Panel (a) estimates $\Delta z_{k(j) i t}=\alpha_{j}+\alpha_{s q}+\beta \varepsilon_{t}^{\mathrm{F}}+\gamma \theta_{k(j) i t} \varepsilon_{t}^{\mathrm{F}}+\Gamma^{\prime} Z_{j t}+u_{j i t}$, where $\Delta z_{k(j) i t}$ is the changes in bond option-adjusted spreads, $\varepsilon_{t}^{\mathrm{F}}$ is the narrow HF shock; $\theta_{k(j) i t}$ is the holdings of bond $k$ by intermediary $i$; $\alpha_{j}$ is a firm fixed effect; $\alpha_{s t}$ is a sector-by-quarter fixed effect; and $Z_{j t}$ is a vector of bond controls including bond holdings $\theta_{k(j) i t}$, a categorical variable for bond ratings, remaining maturity, average spreads in the previous 30 days, and month-to-date changes in spreads. Panel (b) estimates $\Delta y_{j t}=\alpha_{j}+\beta_{w} \varepsilon_{t}^{\mathrm{F}} \mathbb{1}\left(\varepsilon_{t}^{\mathrm{F}}>\right.$ $\left.\bar{\varepsilon}_{t}\right)+\beta_{u} \varepsilon_{t}^{\mathrm{F}} \mathbb{1}\left(\varepsilon_{t}^{\mathrm{F}}<\bar{\varepsilon}_{t}\right)+\Gamma^{\prime} Z_{t}+u_{j t}$, where $\varepsilon_{t}^{\mathrm{F}}$ is the narrow HF shock; $\mathbb{1}\left(\varepsilon_{t}^{\mathrm{F}}<\bar{\varepsilon}_{t}\right)$ is an indicator variable for dates on which the market value of intermediaries' net worth is below its HP trend $\bar{\varepsilon}_{t}$; and $Z_{t}$ is a vector of macro controls including output, payrolls, a recession indicator, and their interaction terms with the financial shocks. Panel (c) estimates $\Delta y_{j t}=\alpha_{j}+\alpha_{s q}+\beta \varepsilon_{t}^{\mathrm{F}}+\gamma \mathbb{1}_{x_{j t}} \varepsilon_{t}^{\mathrm{F}}+\Gamma^{\prime} Z_{j t}+u_{j t}$, where $\varepsilon_{t}^{\mathrm{F}}$ is the narrow HF shock, $\mathbb{1}_{x_{j t}}$ is an indicator variable for firms with high leverage, investment-grade credit rating, or high liquidity; $\alpha_{j}$ is a firm fixed effect; $\alpha_{s t}$ is a sector-by-quarter fixed effect; and $Z_{j t}$ is a vector of firm controls including the firm characteristic $\mathbb{1}_{x_{j t}}$, lagged sales growth, lagged size, lagged current assets as a share of total assets, and an indicator for fiscal quarter. In panels (a) and (c), estimated $\hat{\beta}$ and $\hat{\gamma}$ are reported, respectively, as "average effect" and "interaction effect." All standard errors are two-way clustered at shock and firm level and reported in parentheses. ${ }^{*}(p<0.10),{ }^{* *}(p<0.05),{ }^{* * *}(p<0.01)$.

where $\varepsilon_{t}^{\mathrm{F}} \mathbb{1}\left(\varepsilon_{t}^{\mathrm{F}}<\bar{\varepsilon}_{t}\right)$ denotes financial shocks on dates on which the financial system is undercapitalized (i.e., when the market value of intermediaries' net worth is below its HP 
trend $\left.\bar{\varepsilon}_{t}\right)$ and $Z_{t}$ is a vector of macro controls and their interaction with financial shocks. ${ }^{9}$ The coefficients of interest, $\beta_{w}$ and $\beta_{u}$, estimate the effect of financial shocks on the rest of the economy when the financial system is well and undercapitalized, respectively.

Panel (a) of Table 4 displays the results, which shows that the impact of financial shocks is driven by their effects on dates on which the financial system is undercapitalized. When the financial system is well capitalized, the effects of financial shocks on nonfinancial firms are economically small and statistically insignificant. This state dependency indicates that a key component driving the aggregate effects of intermediaries in the economy is the overall condition of the financial system (as stressed, for instance, by Gertler and Kiyotaki, 2010).

\subsection{The role of firms' financial positions}

We also provide evidence that nonfinancial firms' financial positions play an important role in our results, as argued in the literature on models of firms' financial frictions and financial shocks (see, for, example, Khan and Thomas, 2013; Jermann and Quadrini, 2012; Christiano et al., 2014). We do so by documenting how nonfinancial firms' financial positions (leverage, credit risk, and liquidity) affect their responses to financial shocks. ${ }^{10}$ In particular, we estimate the model

$$
\Delta y_{j t}=\alpha_{j}+\alpha_{s q}+\beta \varepsilon_{t}^{\mathrm{F}}+\gamma \varepsilon_{t}^{\mathrm{F}} x_{j t}+\Gamma^{\prime} Z_{j t}+u_{j t}
$$

where the dependent variable, $\Delta y_{j t}$ - as in previous sections - is the log changes in nonfinancial firms' stock prices in the 60-minute window around a financial shock; $\varepsilon_{t}^{\mathrm{F}}$ is the narrow HF financial shock; $x_{j t}$ is an indicator variable for firms with high leverage, investmentgrade credit rating, or high liquidity; $\alpha_{j}$ is a firm fixed effect; $\alpha_{s q}$ is a sector-by-quarter fixed effect; and $Z_{j t}$ is a vector of firm controls that include the firm characteristic $x_{j t}$, lagged sales growth, lagged size, lagged current assets as a share of total assets, and an indicator for fiscal quarter. The coefficient of interest, $\gamma$, measures how the effect of financial shocks depends on a firm's financial position. For this analysis, we expand the sample from S\&P

\footnotetext{
${ }^{9}$ We control for macro variables (output, employment, and recession) to measure the state dependency of financial shocks that are unexplained by business cycles, but our estimates are little changed if we exclude the macro controls.

${ }^{10} \mathrm{~A}$ similar strategy has been used in the literature that analyzes heterogenous effects of monetary policy shocks on nonfinancial firms (Ottonello and Winberry, 2020; Anderson and Cesa-Bianchi, 2020; Jeenas, 2019).
} 
500 nonfinancial constituents to all publicly traded nonfinancial firms in the U.S., which is matched with Compustat firm characteristics. Standard errors are two-way clustered by firm and shock.

Panel (c) of Table 4 reports the results from estimating (6), which show that firms' financial positions tend to affect their responses to financial shocks. Credit risk and liquidity are important sources of heterogeneity for the transmission of financial shocks: Firms with lower credit ratings and lower liquidity are those most affected by financial shocks. We interpret this evidence as suggesting that firms' financial positions (and potentially financial heterogeneity) matter in the transmission of financial shocks. ${ }^{11}$

\section{Concluding Remarks}

In this paper we proposed a new measure of financial shocks, based on HF changes in the market value around intermediaries' earnings announcements. We then exploited the "granularity" of financial shocks, stemming from the fact that U.S. publicly traded financial intermediaries have considerable size, to study the effects of financial shocks on the aggregate economy. We document intermediaries' substantial effects on the market value and borrowing costs of nonfinancial firms. The effects are stronger for firms with high default risk and low liquidity levels and when the financial system is undercapitalized.

The HF financial shocks developed in the paper can be directly used by researchers conducting empirical research on macroeconomics, similar to the large body of evidence developed using HF monetary-policy shocks. Our empirical findings on the effect of intermediaries on the aggregate economy can also be useful when combined with macrofinance models aimed at understanding the role of financial frictions in determining the aggregate transmission of shocks. We leave the combination of models with these empirical estimates for future research.

\footnotetext{
${ }^{11}$ It is worth highlighting that the results presented in this section show that firms' heterogeneity in the response to financial shocks differs from financial heterogeneity in response to the monetary policy shocks documented in previous literature. To facilitate this comparison, Appendix D.2 reports the heterogeneous responses of firms in our sample for high-frequency monetary policy shocks, based on changes in Fed funds futures in a 60-minute window around an FOMC announcement, as in Gorodnichenko and Weber (2016). Consistent with previous studies (e.g., Ottonello and Winberry, 2020), firms with higher credit ratings are more responsive to monetary policy; this is in contrast to firms with lower credit ratings' being the most responsive to financial shocks.
} 


\section{References}

Adrian, T., Etula, E. and Muir, T. (2014). Financial intermediaries and the cross-section of asset returns. Journal of Finance, 69 (6), 2557-2596.

Amiti, M. and Weinstein, D. E. (2011). Exports and financial shocks. Quarterly Journal of Economics, 126 (4), 1841-1877.

Anderson, G. and Cesa-Bianchi, A. (2020). Crossing the credit channel: Credit spreads and firm heterogeneity. Bank of England Working Paper.

Ash, E., Gauthier, G. and Widmer, P. (2021). Text semantics capture political and economic narratives. arXiv Preprint arXiv:2108.01720.

Bernanke, B. S. (1983). Nonmonetary effects of the financial crisis in the propagation of the Great Depression. American Economic Review, 73 (3), 257-276.

- (2018). The real effects of disrupted credit: Evidence from the global financial crisis. Brookings Papers on Economic Activity, 2018 (2), 251-342.

- and Kuttner, K. N. (2005). What explains the stock market's reaction to Federal Reserve policy? Journal of Finance, 60 (3), 1221-1257.

Blei, D., NG, A. and Jordan, M. (2003). Latent Dirichlet allocation. Journal of Machine Learning Research, 3 (Jan), 993-1022.

Borup, D. and Schütte, E. C. M. (2020). In search of a job: Forecasting employment growth using Google Trends. Journal of Business 83 Economic Statistics, pp. 1-15.

Breiman, L. (2001). Random forests. Machine Learning, 45 (1), 5-32.

Brunnermeier, M. K. and SAnnikov, Y. (2014). A macroeconomic model with a financial sector. American Economic Review, 104 (2), 379-421.

Bybee, L., Kelly, B. T., Manela, A. and Xiu, D. (2021). Business news and business cycles. National Bureau of Economic Research.

Campbell, J. Y. and Thompson, S. B. (2008). Predicting excess stock returns out of sample: Can anything beat the historical average? Review of Financial Studies, 21 (4), 1509-1531.

Chodorow-Reich, G. (2014). The employment effects of credit market disruptions: Firm-level evidence from the 2008-9 financial crisis. Quarterly Journal of Economics, 129 (1), 1-59.

Chordia, T. and Shivakumar, L. (2006). Earnings and price momentum. Journal of Financial Economics, 80 (3), 627-656.

Christiano, L. J., Eichenbaum, M. S. and Trabandt, M. (2015). Understanding the Great Recession. American Economic Journal: Macroeconomics, 7 (1), 110-67.

-, Motto, R. and Rostagno, M. (2014). Risk shocks. American Economic Review, 104 (1), $27-65$.

Cochrane, J. H. and Piazzesi, M. (2002). The Fed and interest rates - a high-frequency identification. American Economic Review, 92 (2), 90-95.

Cook, T. and Hahn, T. (1989). The effect of changes in the federal funds rate target on market interest rates in the 1970s. Journal of Monetary Economics, 24 (3), 331-351.

Coval, J. and Stafford, E. (2007). Asset fire sales (and purchases) in equity markets. Journal of Financial Economics, 86 (2), 479-512.

Duffee, G. R. (1998). The relation between treasury yields and corporate bond yield spreads. Journal of Finance, $\mathbf{5 3}$ (6), 2225-2241.

Gabaix, X. and Koijen, R. S. (2020). Granular instrumental variables. National Bureau of Economic Research.

Gentzkow, M., Kelly, B. and Taddy, M. (2019). Text as data. Journal of Economic Literature, $57(3), 535-74$. 
Gertler, M. and Gilchrist, S. (2018). What happened: Financial factors in the great recession. Journal of Economic Perspectives, 32 (3), 3-30.

— and - (2019). The channels of financial distress during the Great Recession: Some evidence on the aggregate effects. Working Paper, Columbia University.

- and Kiyotaki, N. (2010). Financial intermediation and credit policy in business cycle analysis. Handbook of Monetary Economics, 3 (11), 547-599.

Gilchrist, S., YAnkov, V. and ZakrajŠEK, E. (2009). Credit market shocks and economic fluctuations: Evidence from corporate bond and stock markets. Journal of Monetary Economics, 56 (4), 471-493.

Gomes, J. F. (2001). Financing investment. American Economic Review, 91 (5), 1263-1285.

Gorodnichenko, Y. and Weber, M. (2016). Are sticky prices costly? Evidence from the stock market. American Economic Review, 106 (1), 165-99.

Gürkaynak, R. S., Sack, B. P. and Swanson, E. T. (2004). Do actions speak louder than words? The response of asset prices to monetary policy actions and statements. FEDS Working Paper.

Hansen, S., McMahon, M. and Prat, A. (2018). Transparency and deliberation within the FOMC: a computational linguistics approach. Quarterly Journal of Economics, 133 (2), 801870.

Hassan, T. A., Schwedeler, M., Schreger, J. and Tahoun, A. (2021). Sources and transmission of country risk. National Bureau of Economic Research.

Hastie, T., Tibshirani, R. and Friedman, J. (2009). The elements of statistical learning: Data mining, inference, and prediction. Springer Science \& Business Media.

He, Z., Kelly, B. and Manela, A. (2017). Intermediary asset pricing: New evidence from many asset classes. Journal of Financial Economics, 126 (1), 1-35.

- and Krishnamurthy, A. (2012). A model of capital and crises. Review of Economic Studies, 79 (2), 735-777.

- and - (2013). Intermediary asset pricing. American Economic Review, 103 (2), 732-70.

- and - (2018). Intermediary asset pricing and the financial crisis. Annual Review of Financial Economics, 10, 173-197.

HÉBert, B. and Schreger, J. (2017). The costs of sovereign default: Evidence from argentina. American Economic Review, 107 (10), 3119-45.

Hennessy, C. A. and Whited, T. M. (2007). How costly is external financing? Evidence from a structural estimation. Journal of Finance, 62 (4), 1705-1745.

Herreño, J. (2020). The aggregate effects of bank lending cuts. Working Paper, Columbia University.

Hoffman, M., Bach, F. and Blei, D. (2010). Online learning for latent Dirichlet allocation. Advances in Neural Information Processing Systems, 23, 856-864.

Huber, K. (2018). Disentangling the effects of a banking crisis: Evidence from German firms and counties. American Economic Review, 108 (3), 868-98.

JEenAs, P. (2019). Firm balance sheet liquidity, monetary policy shocks, and investment dynamics. Working Paper.

Jermann, U. and Quadrini, V. (2012). Macroeconomic effects of financial shocks. American Economic Review, 102 (1), 238-71.

JoRdÀ, Ò. (2005). Estimation and inference of impulse responses by local projections. American Economic Review, 95 (1), 161-182.

Khan, A. and Thomas, J. K. (2013). Credit shocks and aggregate fluctuations in an economy with production heterogeneity. Journal of Political Economy, 121 (6), 1055-1107.

Khwaja, A. I. and Mian, A. (2008). Tracing the impact of bank liquidity shocks: Evidence from 
an emerging market. American Economic Review, 98 (4), 1413-42.

Kuttner, K. N. (2001). Monetary policy surprises and interest rates: Evidence from the fed funds futures market. Journal of Monetary Economics, 47 (3), 523-544.

Larsen, V. and Thorsrud, L. A. (2019). Business cycle narratives. CESifo Working Paper.

Loughran, T. and McDonald, B. (2011). When is a liability not a liability? Textual analysis, dictionaries, and 10-Ks. Journal of Finance, 66 (1), 35-65.

MAgGiori, M. (2021). International macroeconomics with imperfect financial markets.

MCCracken, M. W. and NG, S. (2016). FRED-MD: A monthly database for macroeconomic research. Journal of Business \&3 Economic Statistics, 34 (4), 574-589.

Morelli, J. M., Ottonello, P. and Perez, D. J. (2021). Global banks and systemic debt crises. National Bureau of Economic Research.

Nakamura, E. and Steinsson, J. . (2018a). Identification in macroeconomics. Journal of Economic Perspectives, 32 (3), 59-86.

— and Steinsson, J. . (2018b). High-frequency identification of monetary non-neutrality: The information effect. Quarterly Journal of Economics, 133 (3), 1283-1330.

Ottonello, P. and Winberry, T. (2020). Financial heterogeneity and the investment channel of monetary policy. Econometrica, 88 (6), 2473-2502.

Reinhart, C. M. and Rogoff, K. S. . (2009a). This time is different. Princeton University Press.

- and Rogoff, K. S. . (2009b). The aftermath of financial crises. American Economic Review, 99 (2), 466-72.

Rigobon, R. (2003). Identification through heteroskedasticity. Review of Economics and Statistics, 85 (4), 777-792.

- and SACK, B. (2004). The impact of monetary policy on asset prices. Journal of Monetary Economics, 51 (8), 1553-1575.

Röder, M., Both, A. and Hinneburg, A. (2015). Exploring the space of topic coherence measures. In Proceedings of the Eighth ACM International Conference on Web Search and Data Mining, pp. 399-408.

Siriwardane, E. N. (2019). Limited investment capital and credit spreads. Journal of Finance, 74 (5), 2303-2347.

Zou, H. and Hastie, T. (2005). Regularization and variable selection via the elastic net. Journal of the Royal Statistical Society: Series B (Statistical Methodology), 67 (2), 301-320. 


\section{Appendices}

\section{A. An Illustrative Theoretical Framework}

In this section, we consider a model that motivates our empirical analysis. We use the model to show how our empirical analysis can inform the degree of financial frictions faced by intermediaries, which ultimately govern their role in the macroeconomy. We also use the model to further discuss the assumptions required to identify the effects of financial shocks in the empirical analysis.

\section{A.1. Environment}

There are two periods, $t=0,1$, and two goods: final and capital goods. There is no uncertainty. The economy is populated by a unit mass of identical households and nonfinancial firms and a discrete set of intermediaries indexed by $i \in \mathcal{I}$.

Households have preferences over consumption given by $c_{0}+\beta c_{1}$, where $c_{t}$ is the consumption of final goods in period $t$ and $\beta \in(0,1)$ is a subjective discount factor. Households start with an initial endowment of final goods of $y_{0}$.

Nonfinancial firms have access to a technology to produce final goods in period 1 using capital input: $y_{1}=z_{1} k_{1}^{\alpha}$, where $z_{1}>0$, and to a linear technology to accumulate capital goods out of the final good. Capital fully depreciates after production. Firms cannot raise equity and can only finance their investment by borrowing from financial intermediaries, in the amount $b_{1}$ and at the price $q_{0}$.

Financial intermediaries are firms owned by households, with an initial endowment of final goods, or net worth, of $n_{i 0}$. They specialize in lending to nonfinancial firms. To finance these loans, intermediaries can also raise external finance from households in the form of deposits, $d_{i 1}$, and equity, $x_{i 0}$, both of which are subject to frictions, modeled following the literature of frictional financial intermediaries (e.g., Gertler and Kiyotaki, 2010; Morelli et al., 2021). On the deposit side, intermediaries face limited liability constraints, which link their deposits to their net worth:

$d_{i 1} \leq \kappa n_{i 0}$, with $\kappa \geq 0$. On the equity side, intermediaries face a cost to raise equity $\phi\left(\frac{x_{i 0}}{n_{i 0}}\right)$. As in the quantitative corporate finance literature (e.g., Gomes, 2001; Hennessy and Whited, 2007), these costs are designed to capture flotation costs, adverse-selection premia, and other costs associated with raising external finance. The parameter $\phi \geq 0$ governs the degree of intermediaries' frictions to raise external finance and is a key object in our analysis. The case of $\phi=0$ corresponds to a 
frictionless case that is isomorphic to an economy in which households directly finance firms.

\section{A.2. Optimization}

Households In period 0, after perceiving their initial endowment and the net transfers from their initial ownership of nonfinancial firms and intermediaries, households choose their investments in financial securities: deposits on financial intermediaries, $d_{1}$, and shares of nonfinancial firms and intermediaries, $a_{f 1}$ and $a_{i 1}$. Households' problem is then given by

$$
\begin{aligned}
\max _{d_{i 1}, a_{f 1}, a_{i 1}} & c_{0}+\beta c_{1} \\
\text { s.t. } & c_{0}+p_{f 0} a_{1}+\sum_{i \in \mathcal{I}} p_{i 0} a_{i 1}+d_{1}=y_{0}+\pi_{f 0}+\sum_{i \in \mathcal{I}} \pi_{i 0} \\
& c_{1}=\pi_{f 1} a_{1}+\sum_{i \in \mathcal{I}} a_{i 1} \pi_{i 1}+R_{d} d_{1},
\end{aligned}
$$

where households' initial shares of nonfinancial firms and financial intermediaries have been normalized to one; $\pi_{f t}$ and $\pi_{i t}$ denote the net transfers from nonfinancial firms and intermediary $i$ to households in period $t ; p_{f 0}$ and $p_{i 0}$ denote the price of shares of nonfinancial firms and financial intermediary $i$ in period 0 ; and $R_{d}$ denotes the gross interest rate on deposits. Households' optimal choice of financial securities implies that

$$
R_{d}=\frac{1}{\beta}, \quad p_{f 0}=\beta \pi_{f 1}, \quad p_{i 0}=\beta \pi_{i 1},
$$

which determine the equilibrium deposit rate and share prices.

Nonfinancial firms In period 0, nonfinancial firms choose the capital to produce in the following period, $k_{1}$. Their problem is given by

$$
\begin{aligned}
\max _{k_{1} \geq 0, b_{1}, \pi_{f 0} \geq 0} & \pi_{f 0}+\beta \pi_{f 1} \\
\text { s.t. } & \pi_{f 0}=q_{0} b_{1}-k_{1} \\
& \pi_{f 1}=z_{1} k_{1}^{\alpha}-b_{1},
\end{aligned}
$$


where $b_{1}$ denotes nonfinancial firms' borrowing from financial intermediaries at the price $q_{0}$. Nonfinancial firms' choice of capital is characterized by the Euler equation

$$
\frac{1}{q_{0}}=z_{1} \alpha k_{1}^{\alpha-1}
$$

which equates the marginal cost of capital - given by the interest rate on borrowing $\frac{1}{q_{0}}$, because borrowing is the marginal source of financing - to its marginal benefit (because of the assumed properties for the production technology, the nonnegative dividend constraint is always binding).

Financial intermediaries Given its initial net worth $n_{i 0}$, the problem of financial intermediary $i$ is given by

$$
\begin{array}{ll}
\max _{x_{i 0}, b_{i 1}} & \pi_{i 0}+\beta \pi_{i 1} \\
\text { s.t. } & \pi_{i 0}=-x_{i 0}\left(1+\mathbb{1}_{\left\{x_{i 0}>0\right\}} \phi\left(\frac{x_{i 0}}{n_{i 0}}\right)\right), \\
& \pi_{i 1}=b_{i 1}-R_{d} d_{i 1} \\
& q_{0} b_{i 1}=n_{i 0}+x_{i 0}+d_{i 1} \\
& d_{i 1} \leq \kappa n_{i 0}
\end{array}
$$

where $b_{i 1}$ is the lending by intermediary $i$ to nonfinancial firms. In an interior solution with $x_{i 0}>0$, intermediaries' optimal allocation is characterized by

$$
\begin{aligned}
1+2 \phi\left(\frac{x_{i 0}}{n_{i 0}}\right) & =\beta R_{d}+\mu_{i} \\
\beta R_{d}+\mu_{i} & =\beta \frac{1}{q_{0}},
\end{aligned}
$$

with complementary slackness condition

$$
\left(d_{i 1}-\kappa n_{i 0}\right) \mu_{i}=0
$$

where $\mu_{i}$ denotes the Lagrange multiplier associated with the limited liability constraint of intermediary $i$. Equation (12) implies that intermediaries equate the marginal costs of the two sources of financing: the marginal cost of raising equity with the shadow marginal cost of deposits. In addition, Equation (13) implies that intermediaries equate the marginal cost of external finance with the return on lending. Note that (12) and (13) imply that when the rate on lending exceeds 
the deposit rate $\left(\frac{1}{q_{0}}>R_{d}\right)$, limited liability constraints bind $\left(\mu_{i}>0\right.$ for all $\left.i\right)$ and all intermediaries raise the same external finance relative to their net worth $\chi_{0} \equiv \frac{x_{i 0}}{n_{i 0}}$.

\section{A.3. Equilibrium}

To define the equilibrium, we normalize the total mass of shares of nonfinancial firms and each financial intermediary to one. The equilibrium in this economy is then defined as follows:

Definition 1. Given intermediaries' initial net worth $\left(n_{i 0}\right)_{i \in \mathcal{I}}$, an equilibrium is a set of households' allocations $\left\{c_{0}, c_{1}, d_{1}, a_{f 1},\left(a_{i 1}\right)_{i \in \mathcal{I}}\right\}$; nonfinancial firms' allocations $\left\{\pi_{f 0}, \pi_{f 1}, b_{1}, k_{1}\right\}$; financial intermediaries' allocations $\left(\pi_{i 0}, \pi_{i 1}, d_{i 0}, x_{i 0}, b_{i 1}\right)_{i \in \mathcal{I}}$; and prices $\left\{q_{0}, p_{f 0}, p_{i 0}\right\}$ such that

i. Given prices, households' allocations solve (7); nonfinancial firms' allocations solve (9); and financial intermediaries' allocations solve (11).

ii. Asset markets clear-i.e., $b_{1}=\sum_{i \in \mathcal{I}} b_{i 1}, d_{1}=\sum_{i \in \mathcal{I}} d_{i 1}, a_{f 1}=1$, and $a_{i 1}=1$ for all $i$.

We represent the equilibrium of the model using a demand-supply-of-funds scheme (similar to that developed by Morelli et al., 2021). On the side of intermediaries, focusing on the equilibrium in which their limited liability constraints bind, by integrating intermediaries' flow-of-funds constraints and imposing market clearing for the debt market, we obtain a relationship between capital $k_{1}$ and interest rates $\frac{1}{q_{0}}$ that we label as the aggregate supply of funds:

$$
\mathcal{K}^{s}\left(q_{0}, N_{0}, \phi\right)=N_{0}\left(1+\kappa+\mathcal{X}\left(q_{0}, \phi\right)\right)
$$

where $\mathcal{K}^{s}\left(q_{0}, N_{0}, \phi\right)=q_{0} \sum_{i \in \mathcal{I}} b_{i 0} ; N_{0}=\sum_{i \in \mathcal{I}} n_{i 0}$ denotes aggregate net worth; and $\mathcal{X}\left(q_{0}, \phi\right)=$ $\frac{1}{2 \phi}\left(\beta \frac{1}{q_{0}}-1\right)$. The relationship between the supply of funds and interest rates is upward sloping for $\phi>0$ (i.e., $\frac{\partial \mathcal{K}^{s}\left(q_{0}, N_{0}, \phi\right)}{\partial\left(1 / q_{0}\right)}>0$ ) because, in this case, intermediaries face an upward-sloping cost to raise external finance (governed by $\phi$ ), which implies that to supply more funds, the returns on lending must be larger. On the side of firms, the Euler equation for capital (10) implies a relationship between capital and interest rates, which we label the aggregate demand of funds: $\mathcal{K}^{d}\left(q_{0}\right)=\left(q_{0} z_{1} \alpha\right)^{\frac{1}{1-\alpha}}$. This relationship between the demand of funds and interest rates is downward sloping (i.e., $\frac{\partial \mathcal{K}^{d}\left(q_{0}\right)}{\partial\left(1 / q_{0}\right)}<0$ ), which reflects the fact that lower borrowing costs decrease the marginal cost of capital and are associated with higher investment by firms. Figure A.1a represents the equilibrium capital and interest rates as the intersection between the aggregate supply and demand of funds. 
Figure A.1: The Aggregate Effects of Financial Shocks and The Degree of Intermediaries' Financial Frictions

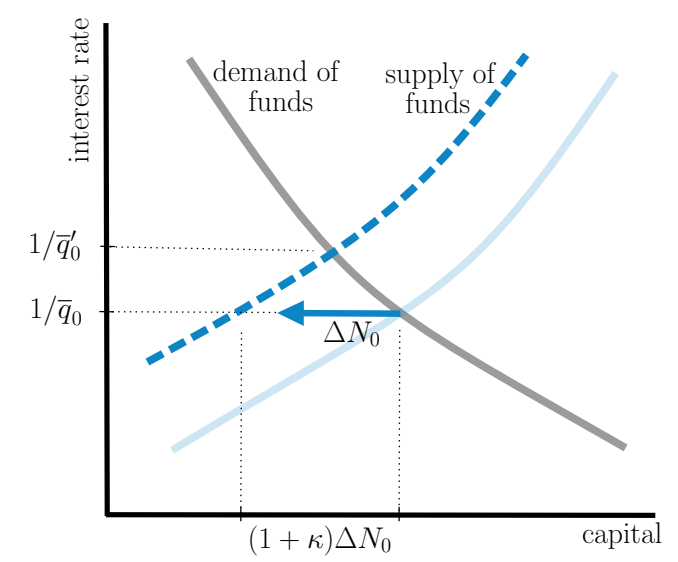

(a) The Aggregate Effects of Financial Shocks

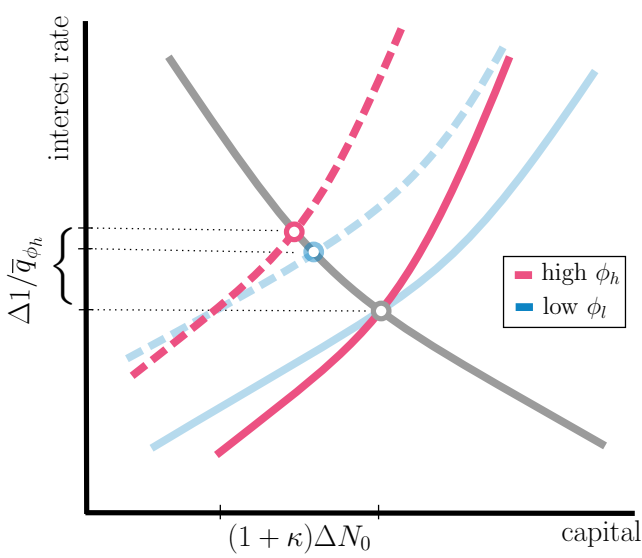

(b) The Role of Intermediaries' Frictions

\section{A.4. The real effects of financial shocks: Model and empirical analysis}

Effects in the model Consider now a "financial shock," an unexpected change in the initial idiosyncratic net worth of some intermediary $\iota \in \mathcal{I}$. Since each intermediary has a mass of net worth, the change in some intermediary's net worth leads to a change in the initial aggregate net worth (i.e., $\frac{\partial N_{0}}{\partial n_{\iota 0}}>0$ ) — this is the assumption we refer to in the empirical analysis as "granularity." Given that the model features aggregation across intermediaries, we can analyze the effect of this idiosyncratic shock by analyzing the effect of a change in the aggregate net worth $N_{0}$.

Panel (a) of Figure A.1 represents the effect of a contraction in the initial aggregate net worth $N_{0}$ in the equilibrium investment and interest rates. This shock implies that financial intermediaries have fewer internal resources to lend, which reduces the aggregate supply of funds for a given level of interest rates and increases equilibrium interest rates. Panel (b) shows that the aggregate effects of the shock on investment and interest rates depend on intermediaries' degree of financial frictions, measured by the marginal cost of external finance $\phi$. Economies in which intermediaries have a higher marginal cost of external finance $\phi$ have a steeper aggregate supply of funds curve because intermediaries require a larger increase in interest rates in order to issue external finance to finance lending to nonfinancial firms. Changes in the initial aggregate net worth have a larger impact on investment because financial intermediaries require higher increases in interest rates to be willing to recapitalize by raising external finance. In economies with a smaller $\phi$, intermediaries face a flatter marginal cost curve of external finance; changes in the initial net worth of intermediaries have a smaller impact on investment because intermediaries can more easily recapitalize, and they 
require a smaller increase in interest rates to be willing to recapitalize and increase lending. In the extreme case in which intermediaries face no cost of external finance, the aggregate supply of funds becomes perfectly elastic, and changes in the initial net worth of intermediaries have no effects on investment or interest rates. The following proposition formalizes this result.

Proposition 1. If $\phi=0$, then $\frac{\partial k_{1}}{\partial N_{0}}=0$. If $\phi>0$ and for large enough $z_{1}$ such that intermediaries' limited liability constraints bind (i.e., $\mu_{i}>0$ for all $i$ ), then $\frac{\partial k_{1}}{\partial N_{0}}>0$ with $\partial \frac{\partial k_{1}}{\partial N_{0}} / \partial \phi>0$ for $\phi \rightarrow 0$.

Proof. See Section A.5.

This discussion suggests that analyzing the macroeconomic effects of idiosyncratic financial shocks - as we do in our empirical analysis - is highly informative on the degree of financial frictions faced by intermediaries. We next discuss the link between the model experiment and the empirical analysis in more detail.

Link to empirical analysis Our high-frequency identification strategy aims to isolate idiosyncratic changes in the net worth of intermediaries, as in the model experiment above. Due to data availability, the empirical analysis focuses on changes in the market value of net worth, while the shock in the model is to the book value $n_{i 0}$. However, in the model there is a tight link between these two objects: Combining with intermediaries' flow of funds constraints under binding limited liability constraints, the price of shares of intermediaries is given by $p_{i 0}=\beta n_{i 0}\left(\frac{1+\chi_{0}+\kappa}{q_{0}}-\frac{1}{\beta} \kappa\right)$. The empirical analysis also focuses on the market value of nonfinancial firms, which in the model has a tight link with nonfinancial firms' capital: Using (A.4) and nonfinancial firms' flow-of-funds constraint, we can express the share price of nonfinancial firms as $p_{f 0}=\beta\left(z_{1} k_{1}^{\alpha}-b_{1}\right)=\beta(1-\alpha) z_{1} k_{1}^{\alpha}$. It follows that the same characterization of responses in the previous section for $k_{1}$ also applies to $p_{f 0} \cdot$

The model experiment helps clarify the main assumptions needed to identify the effects of financial shocks on the real economy. First, changes in individual intermediaries' net worth in the model affect the aggregate net worth. For this reason, our empirical analysis focuses on large intermediaries, which are likely to satisfy this condition. Second, the model experiment considers intermediaries' idiosyncratic net worth changes while keeping fixed nonfinancial firms' productivity $z_{1}$. In the empirical analysis, we provide evidence that our results are not driven by an "information channel" by which the effects of $n_{i 0}$ on $p_{f 0}$ are driven by information about $z_{1}$. We also provide evidence that changes in the market value of intermediaries releasing earnings are driven primarily by idiosyncratic factors and not by nonfinancial macroeconomic factors. 


\section{A.5. Proofs}

Proof of Proposition 1.

Proof. First, if $\phi=0$, then intermediaries' optimality conditions (12) and (13) imply that $q_{0}=\beta$. Nonfinancial firms' optimality condition (10) implies that $1=\beta z_{1} \alpha k_{1}^{\alpha-1}$, meaning that $\frac{\partial k_{1}}{\partial N_{0}}=0$.

For $\phi>0$, conjecture that for large enough $z_{1}$, intermediaries' limited liability constraints bind $\left(\mu_{i}>0\right.$ for all $\left.i\right)$. From (12), in such equilibria, all intermediaries raise the same external finance relative to their net worth $\chi_{0} \equiv \frac{x_{i 0}}{n_{i 0}}$. Combining (10) and (15), we obtain an implicit function that determines equilibrium capital as a function of aggregate net worth $\mathcal{K}\left(k_{1}, N_{0}, \phi\right)=0$, with

$$
\mathcal{K}\left(k_{1}, N_{0}, \phi\right)=k_{1}-N_{0}\left(1+\kappa+\frac{1}{2 \phi}\left(\beta z_{1} \alpha k_{1}^{\alpha-1}-1\right)\right) .
$$

Note that $\frac{\partial \mathcal{K}\left(k_{1}, N_{0}, \phi\right)}{\partial k_{1}}=1-N_{0} \frac{1}{2 \phi} \beta z_{1}(\alpha-1) k_{1}^{\alpha-2}>0$; and that $\frac{\partial \mathcal{K}\left(k_{1}, N_{0}, \phi\right)}{\partial N_{0}}=-\left(1+\kappa+\frac{1}{2 \phi}\left(\beta z_{1} \alpha k_{1}^{\alpha-1}-1\right)\right)$, which, around an equilibrium around which financial intermediaries raise equity, is negative. By the implicit function theorem, it follows that $\frac{\partial k_{1}}{\partial N_{0}}>0$, as stated in the proposition. Using these expressions, it follows that $\operatorname{sign}\left(\partial \frac{\partial k_{1}}{\partial N_{0}} / \partial \phi\right)=N_{0} \frac{1}{2} \beta z_{1}(1-\alpha) k_{1}^{\alpha-2}-\phi \chi_{0}$, which is positive for $\phi \rightarrow 0$.

Finally, we verify the conjecture that for large enough $z_{1}$, intermediaries' limited liability constraints bind. We do so by contradiction. Assume that, contrary to our conjecture, intermediaries' limited liability constraints do not bind for any $z_{1}$. In such equilibrium, by (12), intermediaries do not raise external finance (i.e., $x_{i 0}=0$ for all $i$ ); and by (13), $q_{0}=\beta$. Given $N_{0}$, let $k_{1}^{*}=N_{0}(1+\kappa)$ be the maximum level of capital that satisfies the limited liability constraint without external equity. Let $z_{1}^{*}$ denote the level of productivity that satisfies nonfinancial firms' Euler equation (10) $\frac{1}{\beta}=z_{1}^{*} \alpha\left(k_{1}^{*}\right)^{\alpha-1}$. Consider now some level of productivity $\hat{z}_{1}>z_{1}^{*}$. Let $\hat{k}_{1}$ denote the level of capital that satisfies nonfinancial firms' Euler equation (10) $\frac{1}{\beta}=\hat{z}_{1} \alpha\left(\hat{k}_{1}\right)^{\alpha-1}$. Since $\hat{k}_{1}>k_{1}^{*}$, it follows that $\hat{k}_{1}>N_{0}(1+\kappa)$, which contradicts the assumption that the limited liability constraint does not bind. 


\section{B. Additional Tables and Figures}

Table B.1: Earning Releases of the Financial Intermediaries Used in Our Sample

\begin{tabular}{lll}
\hline \multicolumn{1}{c}{ 1998Q1 } & \multicolumn{1}{c}{ 1998Q2 } & \multicolumn{1}{c}{ 1998Q3 } \\
\hline 07jan1998 19:20:00 LEH & 13apr1998 18:36:00 FCN & 13jul1998 18:59:00 FCN \\
07jan1998 19:20:07 MWD & 13apr1998 18:36:00 MER & 14jul1998 18:48:00 KRB \\
13jan1998 19:33:00 KRB & 14apr1998 19:38:00 KRB & 14jul1998 18:48:00 MER \\
15jan1998 20:13:00 USB & 14apr1998 19:38:00 JPM & 14jul1998 18:48:00 JPM \\
15jan1998 20:13:00 BKB & 15apr1998 20:27:00 BAC & 15jul1998 19:19:00 BAC \\
20jan1998 21:02:00 CMB & 15apr1998 20:28:00 USB & 15jul1998 19:20:00 USB \\
20jan1998 21:06:00 NTRS & 16apr1998 19:43:00 BKB & 15jul1998 19:21:00 WB \\
25mar1998 18:44:00 LEH & 16apr1998 19:46:00 KEY & 16jul1998 19:19:00 BKB \\
26mar1998 19:43:00 MWD & 20apr1998 19:07:00 NTRS & 16jul1998 19:21:00 KEY \\
& 21apr1998 20:01:00 CMB & 20jul1998 19:27:00 NTRS \\
& 21apr1998 20:01:00 CCI & 21jul1998 19:40:00 CCI \\
& 21apr1998 20:06:00 WFC & 21jul1998 19:40:00 CMB \\
& 21apr1998 20:06:00 WB & 21jul1998 19:46:00 WFC \\
& 18jun1998 17:53:00 LEH & 23sep1998 09:32:00 LEH \\
& 18jun1998 17:53:00 MWD & 24sep1998 08:58:00 MWD
\end{tabular}

\begin{tabular}{lll}
\multicolumn{1}{c}{ 1998Q4 } & \multicolumn{1}{c}{ 1999Q1 } & \multicolumn{1}{c}{ 1999Q2 } \\
07oct1998 11:34:00 KRB & 07jan1999 09:06:00 LEH & 13apr1999 09:59:00 MER \\
13oct1998 09:11:00 MER & 07jan1999 09:08:00 MWD & 13apr1999 12:55:00 KRB \\
14oct1998 12:09:00 WB & 14jan1999 08:45:00 WB & 14apr1999 09:15:00 JPM \\
15oct1998 10:23:00 KEY & 19jan1999 08:49:00 ONE & 14apr1999 09:24:00 WB \\
15oct1998 11:16:00 BKB & 19jan1999 09:03:00 MER & 14apr1999 10:53:00 USB \\
19oct1998 08:46:00 NTRS & 19jan1999 09:18:00 BAC & 15apr1999 09:39:00 BKB \\
19oct1998 08:50:00 JPM & 19jan1999 09:19:00 KEY & 15apr1999 09:56:00 KEY \\
20oct1998 08:18:00 WFC & 19jan1999 09:30:00 WFC & 19apr1999 09:02:00 C \\
20oct1998 08:51:00 CMB & 19jan1999 09:36:00 NTRS & 19apr1999 09:10:00 BAC \\
21oct1998 08:38:00 CCI & 19jan1999 09:40:00 JPM & 19apr1999 09:12:00 NTRS \\
22oct1998 09:35:00 USB & 19jan1999 09:43:00 CMB & 20apr1999 09:07:00 ONE \\
& 20jan1999 08:53:00 USB & 20apr1999 09:19:00 WFC \\
& 21jan1999 09:57:00 BKB & 20apr1999 09:31:00 CMB \\
& 25jan1999 09:06:00 C & 22jun1999 09:46:00 LEH \\
& 19mar1999 09:11:00 LEH & 24jun1999 09:02:00 MWD \\
& 25mar1999 08:57:00 MWD & \\
\hline
\end{tabular}

\section{Q3}

13jul1999 08:22:00 MER 13jul1999 13:49:00 KRB 14jul1999 09:25:00 USB 14jul1999 09:27:00 WB 15jul1999 08:18:00 KEY 15jul1999 08:19:00 BKB 19jul1999 09:30:00 C 19jul1999 09:40:00 BAC 19jul1999 09:45:00 WFC 19jul1999 09:58:00 JPM 19jul1999 09:58:00 NTRS 20jul1999 08:39:00 ONE 21jul1999 07:46:00 CMB 21sep1999 09:48:00 GS 22sep1999 09:20:00 MWD 23sep1999 09:09:00 LEH

1999Q4
07oct1999 13:49:00 KRB 12oct1999 08:37:00 MER 13oct1999 08:52:00 WB 14oct1999 09:30:00 USB 18oct1999 09:04:00 JPM 18oct1999 09:07:00 C 18oct1999 09:10:00 BAC 18oct1999 09:27:00 NTRS 19oct1999 09:04:00 ONE 19oct1999 09:22:00 WFC 20oct1999 09:15:00 CMB 21oct1999 09:54:00 KEY 20dec1999 12:17:00 MWD 21dec1999 09:33:00 GS

2000Q1

06jan2000 09:36:00 LEH 10jan2000 13:47:00 KRB 18jan2000 09:30:00 C 18jan2000 09:42:00 ONE 18jan2000 09:47:00 BAC 18jan2000 09:50:00 WFC 18jan2000 09:56:00 JPM 18jan2000 10:03:00 USB 18jan2000 10:56:00 NTRS 19jan2000 09:10:00 KEY 19jan2000 09:16:00 CMB 19jan2000 09:26:00 WB 19jan2000 09:42:00 FBF 25jan2000 09:34:00 MER 20mar2000 09:20:00 LEH 21mar2000 09:03:00 GS 23mar2000 09:12:00 MWD

2000Q2

12apr2000 08:43:00 JPM 12apr2000 14:24:00 KRB 14apr2000 09:37:00 FBF 17apr2000 09:04:00 C

17apr2000 09:13:00 BAC 17apr2000 09:14:00 MER 17apr2000 10:18:00 NTRS 17apr2000 10:26:00 USB 18apr2000 09:16:00 ONE 18apr2000 09:28:00 WFC 19apr2000 08:27:00 CMB 19apr2000 08:47:00 WB 20apr2000 09:19:00 KEY 16jun2000 09:20:00 LEH 20jun2000 08:44:00 GS 22jun2000 08:57:00 MWD 25mar1999 08:57:00 MWD

2000Q3

12jul2000 11:36:00 KRB 13jul2000 09:30:00 JPM 17jul2000 08:47:00 FBF 17jul2000 08:50:00 BAC 17jul2000 09:24:00 NTRS 18jul2000 08:01:00 WFC 18jul2000 08:22:00 KEY 18jul2000 08:25:00 MER 19jul2000 08:27:00 C 19jul2000 08:32:00 CMB 19jul2000 08:54:00 ONE 19jul2000 09:14:00 WB 20jul2000 10:00:00 USB 19sep2000 09:13:00 GS 20sep2000 16:56:00 LEH 21sep2000 08:49:00 MWD

2000Q4
11oct2000 09:02:00 KRB
16oct2000 09:17:00 NTRS
16oct2000 10:45:00 BAC
17oct2000 07:14:00 C
17oct2000 07:52:00 KEY
17oct2000 07:53:00 MER
17oct2000 08:10:00 ONE
17oct2000 08:16:00 WFC
17oct2000 08:42:00 FBF
18oct2000 09:03:00 JPM
18oct2000 09:05:00 CMB
18oct2000 09:33:00 WB
19oct2000 09:07:00 USB
19dec2000 08:54:00 MWD
19dec2000 19:15:00 GS

.

\section{Q1}

10jan2001 11:46:00 KRB 16jan2001 08:43:00 C 16jan2001 08:53:00 KEY 16jan2001 09:00:00 BAC 16jan2001 09:07:00 WFC 16jan2001 09:17:00 NTRS 17jan2001 09:30:00 FBF 17jan2001 09:43:00 WB 17jan2001 17:17:00 ONE 18jan2001 10:13:00 USB 23jan2001 09:07:00 MER 20mar2001 08:54:00 GS 21mar2001 09:11:00 LEH 21mar2001 09:17:00 MWD

\begin{tabular}{ll}
\multicolumn{1}{c}{ 2001Q2 } & \multicolumn{1}{c}{ 2001Q3 } \\
11apr2001 09:09:00 KRB & 11jul2001 08:23:00 WB \\
16apr2001 08:18:00 C & 12jul2001 08:50:00 KRB \\
16apr2001 09:30:00 BAC & 16jul2001 08:24:00 BAC \\
16apr2001 09:42:00 NTRS & 16jul2001 08:48:00 C \\
16apr2001 10:02:00 WB & 16jul2001 08:53:00 NTRS \\
17apr2001 07:53:00 FBF & 17jul2001 08:08:00 MER \\
17apr2001 08:42:00 ONE & 17jul2001 08:28:00 ONE \\
17apr2001 08:56:00 WFC & 17jul2001 08:55:00 KEY \\
17apr2001 13:12:00 USB & 17jul2001 15:18:00 USB \\
18apr2001 08:45:00 JPM & 17jul2001 18:28:00 WFC \\
18apr2001 09:07:00 KEY & 18jul2001 06:45:00 FBF \\
18apr2001 09:25:00 MER & 18jul2001 08:52:00 JPM \\
19jun2001 08:31:00 GS & 21sep2001 08:32:00 MWD \\
19jun2001 12:12:00 LEH & 25sep2001 08:23:00 LEH \\
21jun2001 08:29:00 MWD & 26sep2001 08:45:00 GS
\end{tabular}

\begin{tabular}{|c|c|c|c|}
\hline 2001Q3 & 2001Q4 & 2002Q1 & 2002Q2 \\
\hline 11jul2001 08:23:00 WB & 04oct2001 10:49:00 MER & 10jan2002 11:40:00 KRB & 11apr2002 13:02:00 KRB \\
\hline 12jul2001 08:50:00 KRB & 11oct2001 14:40:00 KRB & 14jan2002 11:00:00 NTRS & 15apr2002 06:55:00 C \\
\hline 16jul2001 08:24:00 BAC & 15oct2001 07:36:00 BAC & 15jan2002 10:04:00 WFC & 15apr2002 07:17:00 BAC \\
\hline 16jul2001 08:48:00 C & 15oct2001 08:35:00 NTRS & 15jan2002 17:35:00 USB & 15apr2002 08:43:00 NTRS \\
\hline 16jul2001 08:53:00 NTRS & 16oct2001 08:28:00 ONE & 16jan2002 06:58:00 KEY & 16apr2002 06:37:00 FBF \\
\hline 17jul2001 08:08:00 MER & 16oct2001 08:48:00 WFC & 16jan2002 18:54:00 JPM & 16apr2002 08:30:00 ONE \\
\hline 17jul2001 08:28:00 ONE & 16oct2001 11:06:00 USB & 16jan2002 18:55:00 ONE & 16apr2002 08:47:00 WFC \\
\hline 17jul2001 08:55:00 KEY & 17oct2001 06:17:00 C & 17jan2002 08:54:00 C & 16apr2002 12:18:00 USB \\
\hline 17jul2001 15:18:00 USB & 17oct2001 07:20:00 FBF & 22jan2002 07:50:00 BAC & 17apr2002 07:28:00 JPM \\
\hline 17jul2001 18:28:00 WFC & 17oct2001 07:34:00 JPM & 23jan2002 07:26:00 WB & 17apr2002 07:57:00 MER \\
\hline 18jul2001 06:45:00 FBF & 17oct2001 08:01:00 KEY & 23jan2002 08:14:00 MER & 17apr2002 08:12:00 KEY \\
\hline 18jul2001 08:52:00 JPM & 19dec2001 08:24:00 MWD & 29jan2002 06:59:00 FBF & 18apr2002 07:52:00 WB \\
\hline 21sep2001 08:32:00 MWD & 20dec2001 08:21:00 GS & 19mar2002 08:23:00 GS & 18jun2002 07:27:00 LEH \\
\hline 25sep2001 08:23:00 LEH & 20dec2001 09:29:00 LEH & 20mar2002 08:19:00 LEH & 19jun2002 08:29:00 MWD \\
\hline 26sep2001 08:45:00 GS & & 26mar2002 08:35:00 MWD & 20jun2002 08:56:00 GS \\
\hline 2003Q1 & 2003Q2 & 2003Q3 & 2003Q4 \\
\hline 15jan2003 07:13:00 KEY & 14apr2003 06:12:00 C & 14jul2003 06:52:00 BAC & 14oct2003 07:30:( \\
\hline 15jan2003 07:38:00 BAC & 14apr2003 07:19:00 FBF & 14jul2003 07:38:00 C & 14oct2003 07:56:00 BAC \\
\hline 16jan2003 07:26:00 FBF & 14apr2003 07:30:00 BAC & 15jul2003 05:50:00 WFC & 15oct2003 07:01:00 WB \\
\hline 16jan2003 07:42:00 WB & 15apr2003 07:55:00 ONE & 15jul2003 07:54:00 FBF & 15oct2003 07:26:00 FBF \\
\hline 16jan2003 08:38:00 ONE & 15apr2003 08:37:00 WFC & 15jul2003 09:20:00 MER & 15oct2003 08:32:00 NTRS \\
\hline 21jan2003 06:27:00 C & 15apr2003 09:05:00 NTRS & 15jul2003 12:00:00 USB & 16oct2003 06:42:00 KEY \\
\hline 21jan2003 08:26:00 WFC & 15apr2003 11:54:00 USB & 16jul2003 07:57:00 ONE & 16oct2003 08:40:00 KRB \\
\hline 21jan2003 13:11:00 USB & 16apr2003 07:40:00 WB & 16jul2003 08:12:00 NTRS & 20oct2003 07:33:00 C \\
\hline 22jan2003 07:00:00 JPM & 16apr2003 07:43:00 JPM & 16jul2003 15:48:00 JPM & 21oct2003 07:02:00 USB \\
\hline 22jan2003 08:11:00 MER & 16apr2003 07:47:00 MER & 17jul2003 07:01:00 WB & 21oct2003 08:00:00 WFC \\
\hline 22jan2003 08:36:00 NTRS & 17apr2003 07:53:00 KEY & 18jul2003 06:54:00 KEY & 21oct2003 10:17:00 ONE \\
\hline 23jan2003 10:09:00 KRB & 23apr2003 08:57:00 KRB & 24jul2003 09:11:00 KRB & 22oct2003 07:33:00 JPM \\
\hline 20mar2003 08:24:00 LEH & 18jun2003 14:28:00 MWD & 23sep2003 08:26:00 GS & 17dec2003 08:01:00 LEH \\
\hline 20mar2003 08:33:00 MWD & 19jun2003 08:50:00 LEH & 23sep2003 09:00:00 LEH & 18dec2003 08:05:00 GS \\
\hline 20mar2003 08:53:00 GS & 25jun2003 08:28:00 GS & 23sep2003 09:43:00 MWD & 18dec2003 08:06:00 MWD \\
\hline
\end{tabular}


Table B.1: Earning Releases of the Financial Intermediaries Used in Our Sample (Cont.)

\begin{tabular}{|c|c|c|c|c|c|}
\hline 2004Q1 & 2004Q2 & 2004Q3 & 2004Q4 & 2005Q1 & 2005Q2 \\
\hline 15jan2004 05:59:00 BAC & 13apr2004 07:30:00 MER & 13jul2004 07:35:00 MER & 12oct2004 07:33:00 MER & 18jan2005 06:50:00 BAC & 15apr2005 06:00:00 C \\
\hline 15jan2004 06:02:00 WB & 14apr2004 07:00:00 BAC & 14jul2004 07:00:00 BAC & 14oct2004 06:00:00 C & 18jan2005 08:02:00 WFC & 15apr2005 06:30:00 WB \\
\hline 15jan2004 06:45:00 FBF & 15apr2004 06:32:00 KEY & 15jul2004 06:20:00 C & 14oct2004 06:31:00 BAC & 18jan2005 08:56:00 USB & 15apr2005 06:36:00 KEY \\
\hline 20jan2004 07:50:00 C & 19apr2004 07:06:00 WB & 16jul2004 06:23:00 KEY & 15oct2004 15:26:00 WB & 19jan2005 06:51:00 JPM & 19apr2005 07:29:00 MER \\
\hline 20jan2004 07:58:00 ONE & 20apr2004 08:13:00 NTRS & 20jul2004 08:01:00 WFC & 19oct2004 08:01:00 WFC & 19jan2005 08:10:00 NTRS & 19apr2005 08:01:00 WFC \\
\hline 20jan2004 08:06:00 WFC & 20apr2004 08:45:00 WFC & 20jul2004 08:31:00 USB & 19oct2004 10:13:00 USB & 20jan2005 06:00:00 C & 19apr2005 08:12:00 NTRS \\
\hline 20jan2004 13:27:00 USB & 20apr2004 11:05:00 USB & 21jul2004 08:04:00 JPM & 20oct2004 07:00:00 JPM & 20jan2005 07:55:00 KRB & 19apr2005 08:45:00 USB \\
\hline 21jan2004 07:31:00 MER & 21apr2004 07:02:00 JPM & 22jul2004 08:35:00 KRB & 21oct2004 08:37:00 KRB & 25jan2005 07:34:00 MER & 21apr2005 17:11:00 KRB \\
\hline 21jan2004 09:27:00 NTRS & 22apr2004 08:33:00 KRB & 21sep2004 08:06:00 LEH & 15dec2004 08:02:00 LEH & 15mar2005 10:17:00 LEH & 14jun2005 08:12:00 LEH \\
\hline 22jan2004 16:31:00 KRB & 15jun2004 08:05:00 LEH & 21sep2004 08:27:00 GS & 16dec2004 08:27:00 GS & 17mar2005 08:15:00 MWD & 16jun2005 08:24:00 GS \\
\hline 16mar2004 09:00:00 LEH & 22jun2004 08:04:00 MWD & 22sep2004 08:10:00 MWD & 21dec2004 08:08:00 MWD & 17mar2005 08:22:00 GS & 22jun2005 08:03:00 MWD \\
\hline 18mar2004 07:59:00 MWD & 22jun2004 08:22:00 GS & & & & \\
\hline
\end{tabular}

18 mar2004 07:59:00 MWD 22jun2004 08:22:00 GS

23mar2004 08:21:00 GS

\begin{tabular}{|c|c|c|c|c|c|}
\hline 2005Q3 & 2005Q4 & 2006Q1 & 2006Q2 & 2006Q3 & 2006Q4 \\
\hline 18jul2005 06:52:00 KRB & 17oct2005 06:00:00 C & 17jan2006 07:45:00 USB & 17apr2006 07:03:00 WB & 17jul2006 06:00:00 C & 16oct2006 07:00:00 WB \\
\hline 18jul2005 07:40:00 BAC & 17oct2005 07:26:00 WB & 17jan2006 08:00:00 WFC & 17apr2006 07:03:00 C & 18jul2006 07:07:00 KEY & 17oct2006 06:58:00 KEY \\
\hline 18jul2005 23:10:00 C & 18oct2005 06:44:00 USB & 18jan2006 07:07:00 JPM & 18apr2006 06:41:00 KEY & 18jul2006 07:30:00 MER & 17oct2006 07:32:00 MER \\
\hline 19jul2005 06:25:00 KEY & 18oct2005 07:32:00 KEY & 18jan2006 08:04:00 NTRS & 18apr2006 07:17:00 USB & 18jul2006 07:45:00 USB & 17oct2006 07:44:00 USB \\
\hline 19jul2005 06:30:00 USB & 18oct2005 08:00:00 WFC & 19jan2006 07:01:00 WB & 18apr2006 07:33:00 MER & 18jul2006 08:36:00 WFC & 17oct2006 08:00:00 WFC \\
\hline 19jul2005 07:03:00 WB & 18oct2005 08:13:00 MER & 19jan2006 07:30:00 MER & 18apr2006 08:00:00 WFC & 19jul2006 06:59:00 JPM & 18oct2006 06:59:00 JPM \\
\hline 19jul2005 07:30:00 MER & 19oct2005 06:40:00 BAC & 20jan2006 06:00:00 C & 18apr2006 08:10:00 NTRS & 19jul2006 07:00:00 BAC & 18oct2006 08:12:00 NTRS \\
\hline 19jul2005 08:00:00 WFC & 19oct2005 06:47:00 KRB & 20jan2006 06:38:00 KEY & 19apr2006 07:10:00 JPM & 19jul2006 08:13:00 NTRS & 19oct2006 06:01:00 C \\
\hline 20jul2005 07:04:00 JPM & 19oct2005 06:59:00 JPM & 23jan2006 06:40:00 BAC & 20apr2006 07:17:00 BAC & 20jul2006 07:19:00 WB & 19oct2006 06:40:00 BAC \\
\hline 20jul2005 08:27:00 NTRS & 19oct2005 08:30:00 NTRS & 26jan2006 17:29:00 AMP & 25apr2006 16:07:00 AMP & 25jul2006 16:21:00 AMP & 24oct2006 16:02:00 AMP \\
\hline 14sep2005 08:14:00 LEH & 24oct2005 06:00:00 AMP & 14mar2006 08:11:00 GS & 12jun2006 08:07:00 LEH & 12sep2006 08:22:00 GS & $12 \mathrm{dec} 2006$ 09:22:00 GS \\
\hline 20sep2005 08:28:00 GS & 13dec2005 08:01:00 LEH & 15mar2006 08:14:00 LEH & 13jun2006 08:24:00 GS & 13sep2006 08:15:00 LEH & 14dec2006 07:35:00 LEH \\
\hline 21sep2005 08:00:00 MWD & $\begin{array}{l}\text { 15dec2005 08:27:00 GS } \\
\text { 20dec2005 08:02:00 MWD }\end{array}$ & 22mar2006 08:00:00 MS & 21jun2006 08:00:00 MS & 20sep2006 08:00:00 MS & 19dec2006 07:45:00 MS \\
\hline 2007Q1 & 2007Q2 & 2007Q3 & $2007 \mathrm{Q4}$ & 2008Q1 & 2008Q2 \\
\hline 16jan2007 08:00:00 WFC & 16apr2007 07:00:00 C & 17jul2007 06:35:00 KEY & 15oct2007 06:30:00 C & 15jan2008 06:30:00 C & 14apr2008 09:39:00 WB \\
\hline 16jan2007 08:30:00 USB & 16apr2007 07:02:00 WB & 17jul2007 07:30:00 MER & 16oct2007 06:30:00 KEY & 15jan2008 08:00:00 USB & 15apr2008 08:00:00 NTRS \\
\hline 17jan2007 08:34:00 NTRS & 17apr2007 08:21:00 NTRS & 17jul2007 08:00:00 WFC & 16oct2007 08:00:00 WFC & 16jan2008 08:00:00 WFC & 16apr2008 06:59:00 JPM \\
\hline 18jan2007 07:30:00 MER & 17apr2007 08:26:00 WFC & 18jul2007 06:59:00 JPM & 17oct2007 07:08:00 JPM & 16jan2008 08:34:00 NTRS & 16apr2008 08:00:00 WFC \\
\hline 19jan2007 07:09:00 C & 17apr2007 10:47:00 USB & 18jul2007 08:21:00 NTRS & 17oct2007 08:23:00 NTRS & 17jan2008 07:07:00 BK & 17apr2008 06:30:00 MER \\
\hline 19jan2007 07:18:00 KEY & 18apr2007 06:59:00 JPM & 19jul2007 07:05:00 BAC & 18oct2007 06:28:00 BK & 17jan2008 07:11:00 MER & 17apr2008 06:30:00 BK \\
\hline 23jan2007 06:04:00 WB & 19apr2007 07:00:00 BAC & 20jul2007 07:00:00 C & 18oct2007 07:01:00 BAC & 22jan2008 06:35:00 KEY & 17apr2008 06:50:00 KEY \\
\hline 23jan2007 06:45:00 BAC & 19apr2007 07:30:00 MER & 20jul2007 07:01:00 WB & 19oct2007 07:01:00 WB & 22jan2008 07:01:00 WB & 18apr2008 06:30:00 C \\
\hline 25jan2007 16:02:00 AMP & 24apr2007 16:01:00 AMP & 25jul2007 16:11:00 AMP & 24oct2007 07:30:00 MER & 22jan2008 07:02:00 BAC & 21apr2008 07:00:00 BAC \\
\hline 13mar2007 08:23:00 GS & 12jun2007 08:10:00 LEH & 18sep2007 08:04:00 LEH & 24oct2007 16:01:00 AMP & 24jan2008 16:29:00 AMP & 22apr2008 16:01:00 AMP \\
\hline 14mar2007 08:08:00 LEH & 14jun2007 08:24:00 GS & 19sep2007 07:30:00 MS & 13dec2007 08:08:00 LEH & 18mar2008 08:00:00 GS & 16jun2008 08:17:00 LEH \\
\hline \multirow[t]{2}{*}{ 21mar2007 07:30:00 MS } & 20jun2007 07:30:00 MS & 20sep2007 08:00:00 GS & 18dec2007 08:17:00 GS & 18mar2008 08:13:00 LEH & 17jun2008 08:25:00 GS \\
\hline & & & 19dec2007 07:30:00 MS & 19mar2008 17:00:00 MS & 18jun2008 08:00:00 MS \\
\hline 2008Q3 & 2008Q4 & 2009Q1 & 2009Q2 & 2009Q3 & 2009Q4 \\
\hline 15jul2008 08:00:00 USB & 06oct2008 16:10:00 BAC & 15jan2009 06:30:00 JPM & 13apr2009 14:10:00 GS & 14jul2009 08:36:00 GS & 14oct2009 06:59:00 JPM \\
\hline 16jul2008 08:00:00 WFC & 15oct2008 06:59:00 JPM & 16jan2009 06:00:00 C & 16apr2009 06:29:00 JPM & 16jul2009 06:29:00 JPM & 15 oct2009 07:15:00 GS \\
\hline 16jul2008 08:07:00 NTRS & 15oct2008 08:00:00 WFC & 16jan2009 07:00:00 BAC & 17apr2009 06:30:00 C & 17jul2009 07:00:00 BAC & 15 oct2009 08:00:00 C \\
\hline 17jul2008 06:29:00 JPM & 16oct2008 06:30:00 MER & 20jan2009 16:35:00 BK & 20apr2009 07:00:00 BAC & 17jul2009 08:00:00 C & 16oct2009 07:00:00 BAC \\
\hline 17jul2008 07:00:00 BK & 16oct2008 06:30:00 BK & 21jan2009 08:00:00 USB & 21apr2009 06:23:00 BK & 22jul2009 06:19:00 WFC & 20oct2009 06:30:00 BK \\
\hline 22jul2008 06:47:00 KEY & 22oct2008 07:00:00 WB & 28jan2009 16:17:00 AMP & 21apr2009 16:01:00 AMP & 22jul2009 08:03:00 MS & 21oct2009 08:01:00 MS \\
\hline 22jul2008 07:00:00 WB & 22oct2008 08:04:00 NTRS & & 22apr2009 07:48:00 MS & 22jul2009 08:12:00 NTRS & 21oct2009 08:07:00 NTRS \\
\hline 23jul2008 16:01:00 AMP & 29oct2008 16:01:00 AMP & & 22apr2009 08:00:00 WFC & 23jul2009 16:01:00 AMP & 21oct2009 16:05:00 AMP \\
\hline 16sep2008 08:15:00 GS & 16dec2008 08:15:00 GS & & & & \\
\hline 16sep2008 16:00:00 MS & 17dec2008 08:00:00 MS & & & & \\
\hline
\end{tabular}


Table B.1: Earning Releases of the Financial Intermediaries Used in Our Sample (Cont.)

\begin{tabular}{lllll}
\hline \multicolumn{1}{c}{ 2010Q1 } & \multicolumn{1}{c}{ 2010Q2 } & \multicolumn{1}{c}{ 2010Q3 } & \multicolumn{1}{c}{ 2010Q4 } & \multicolumn{1}{c}{ 2011Q1 } \\
\hline 15jan2010 06:59:00 JPM & 14apr2010 06:59:00 JPM & 15jul2010 06:29:00 JPM & 13oct2010 06:58:00 JPM & 14jan2011 06:59:00 JPM \\
19jan2010 08:00:00 C & 16apr2010 07:00:00 BAC & 16jul2010 07:00:00 BAC & 18oct2010 08:00:00 C & 18jan2011 08:00:00 C \\
20jan2010 06:30:00 BK & 19apr2010 08:00:00 C & 16jul2010 08:00:00 C & 19oct2010 06:29:00 BK & 19jan2011 06:27:00 BK \\
20jan2010 07:00:00 USB & 20apr2010 06:30:00 BK & 20jul2010 06:30:00 BK & 19oct2010 06:43:00 BAC & 19jan2011 07:15:00 USB \\
20jan2010 07:01:00 BAC & 20apr2010 07:01:00 GS & 20jul2010 08:05:00 GS & 19oct2010 08:01:00 GS & 19jan2011 07:36:00 NTRS \\
20jan2010 08:00:00 WFC & 20apr2010 07:30:00 USB & 21jul2010 07:00:00 USB & 20oct2010 06:45:00 USB & 19jan2011 08:00:00 WFC \\
20jan2010 08:02:00 MS & 20apr2010 07:33:00 NTRS & 21jul2010 08:00:00 WFC & 20oct2010 07:30:00 MS & 19jan2011 08:02:00 GS \\
20jan2010 08:11:00 NTRS & 21apr2010 06:19:00 KEY & 21jul2010 08:00:00 MS & 20oct2010 07:47:00 WFC & 20jan2011 07:30:00 MS \\
21jan2010 07:54:00 KEY & 21apr2010 07:47:00 WFC & 21jul2010 08:13:00 NTRS & 21oct2010 08:01:00 NTRS & 21jan2011 07:03:00 BAC \\
21jan2010 08:00:00 GS & 21apr2010 08:01:00 MS & 22jul2010 06:18:00 KEY & 22oct2010 06:30:00 KEY & 25jan2011 06:33:00 KEY \\
03feb2010 16:05:00 AMP & 26apr2010 16:37:00 AMP & 28jul2010 16:26:00 AMP & 27oct2010 16:05:00 AMP & 02feb2011 16:01:00 AMP
\end{tabular}

\begin{tabular}{|c|c|c|c|c|}
\hline 2011Q2 & 2011Q3 & 2011Q4 & 2012Q1 & 2012Q2 \\
\hline 13apr2011 06:59:00 JPM & 14jul2011 07:00:00 JPM & 13oct2011 06:58:00 JPM & 13jan2012 06:59:00 JPM & 13apr2012 06:58:00 JPM \\
\hline 15apr2011 07:00:00 BAC & 15jul2011 08:00:00 C & 17oct2011 07:59:00 C & 17jan2012 07:59:00 C & 13apr2012 08:03:00 WFC \\
\hline 18apr2011 06:30:00 KEY & 19 jul2011 06:20:00 KEY & 17oct2011 08:00:00 WFC & 17jan2012 08:02:00 WFC & 16apr2012 07:59:00 C \\
\hline 18apr2011 08:00:00 C & 19 jul2011 06:23:00 BK & 18oct2011 07:00:00 BAC & 18jan2012 06:30:00 BK & 17apr2012 07:02:00 USB \\
\hline 19apr2011 06:26:00 BK & 19 jul2011 07:00:00 BAC & 18oct2011 07:35:00 GS & 18jan2012 07:00:00 USB & 17apr2012 07:32:00 NTRS \\
\hline 19apr2011 06:45:00 USB & 19jul2011 08:00:00 GS & 19oct2011 06:30:00 BK & 18jan2012 07:14:00 NTRS & 17apr2012 07:36:00 GS \\
\hline 19apr2011 07:30:00 NTRS & 19jul2011 08:00:00 WFC & 19oct2011 07:00:00 USB & 18jan2012 07:40:00 GS & 18apr2012 06:38:00 BK \\
\hline 19apr2011 08:02:00 GS & 20jul2011 06:59:00 USB & 19oct2011 07:15:00 MS & 19jan2012 07:00:00 BAC & 19apr2012 06:31:00 KEY \\
\hline 20apr2011 08:00:00 WFC & 20jul2011 08:06:00 NTRS & 19oct2011 07:37:00 NTRS & 19jan2012 07:15:00 MS & 19apr2012 07:00:00 BAC \\
\hline 21apr2011 07:15:00 MS & 21jul2011 07:16:00 MS & 20oct2011 06:19:00 KEY & 24jan2012 08:07:00 KEY & 19apr2012 07:15:00 MS \\
\hline 25apr2011 16:05:00 AMP & 27jul2011 16:05:00 AMP & 26oct2011 16:15:00 AMP & 01feb2012 16:05:00 AMP & 23apr2012 16:10:00 AMP \\
\hline 2012Q3 & 2012Q4 & 2013Q1 & 2013Q2 & 2013Q3 \\
\hline 13jul2012 06:59:00 JPM & 12oct2012 07:02:00 JPM & 11jan2013 08:00:00 WFC & 12apr2013 06:59:00 JPM & 12jul2013 06:56:00 JPM \\
\hline 13jul2012 08:02:00 WFC & 12oct2012 08:00:00 WFC & 16jan2013 06:30:00 BK & 12apr2013 08:08:00 WFC & 12jul2013 08:00:00 WFC \\
\hline 16jul2012 07:59:00 C & 15oct2012 08:05:00 C & 16jan2013 06:45:00 USB & 15apr2013 07:59:00 C & 15jul2013 07:59:00 C \\
\hline 17jul2012 07:35:00 GS & 16oct2012 07:35:00 GS & 16jan2013 07:01:00 JPM & 16apr2013 07:00:00 USB & 16jul2013 07:47:00 GS \\
\hline 18jul2012 06:48:00 BK & 17oct2012 07:00:00 USB & 16jan2013 07:35:00 NTRS & 16apr2013 07:30:00 NTRS & 17jul2013 06:30:00 BK \\
\hline 18jul2012 07:00:00 BAC & 17oct2012 07:01:00 BAC & 16jan2013 07:42:00 GS & 16apr2013 07:35:00 GS & 17jul2013 07:00:00 BAC \\
\hline 18jul2012 07:20:00 USB & 17oct2012 07:30:00 NTRS & 17jan2013 07:03:00 BAC & 17apr2013 06:30:00 BK & 17jul2013 07:00:00 USB \\
\hline 18jul2012 07:41:00 NTRS & 17oct2012 08:29:00 BK & 17 jan2013 08:00:00 C & 17 apr2013 07:00:00 BAC & 17jul2013 07:34:00 NTRS \\
\hline 19jul2012 06:30:00 KEY & 18oct2012 06:31:00 KEY & 18jan2013 07:16:00 MS & 18apr2013 06:30:00 KEY & 18jul2013 06:14:00 KEY \\
\hline 19jul2012 07:15:00 MS & 18oct2012 07:25:00 MS & 24jan2013 06:15:00 KEY & 18apr2013 07:15:00 MS & 18jul2013 07:15:00 MS \\
\hline 25jul2012 16:05:00 AMP & 24oct2012 16:05:00 AMP & 30jan2013 16:05:00 AMP & 22apr2013 16:05:00 AMP & 24jul2013 16:05:00 AMP \\
\hline
\end{tabular}

\begin{tabular}{llll}
\hline \multicolumn{1}{c}{ 2013Q4 } & \multicolumn{1}{c}{ 2014Q1 } & \multicolumn{1}{c}{ 2014Q2 } & \multicolumn{1}{c}{ 2014Q3 } \\
\hline 11oct2013 06:58:00 JPM & 14jan2014 06:59:00 JPM & 11apr2014 06:59:00 JPM & 11jul2014 08:00:00 WFC \\
11oct2013 08:00:00 WFC & 14jan2014 08:00:00 WFC & 11apr2014 08:00:00 WFC & 14jul2014 07:59:00 C \\
15oct2013 07:48:00 C & 15jan2014 07:00:00 BAC & 14apr2014 07:59:00 C & 15jul2014 06:59:00 JPM \\
16oct2013 06:30:00 BK & 16jan2014 07:35:00 GS & 15apr2014 07:56:00 NTRS & 15jul2014 07:35:00 GS \\
16oct2013 06:30:00 KEY & 16jan2014 07:59:00 C & 16apr2014 07:00:00 BAC & 16jul2014 07:00:00 BAC \\
16oct2013 07:00:00 BAC & 17jan2014 06:30:00 BK & 16apr2014 07:15:00 USB & 16jul2014 07:15:00 USB \\
16oct2013 07:00:00 USB & 17jan2014 07:15:00 MS & 17apr2014 06:30:00 KEY & 16jul2014 08:05:00 NTRS \\
16oct2013 07:30:00 NTRS & 22jan2014 07:35:00 NTRS & 17apr2014 06:45:00 MS & 17jul2014 06:30:00 KEY \\
17oct2013 07:35:00 GS & 22jan2014 07:38:00 USB & 17apr2014 07:42:00 GS & 17jul2014 07:15:00 MS \\
18oct2013 07:15:00 MS & 23jan2014 06:45:00 KEY & 22apr2014 06:30:00 BK & 18jul2014 06:30:00 BK \\
29oct2013 16:05:00 AMP & 04feb2014 16:05:00 AMP & 28apr2014 16:05:00 AMP & 29jul2014 16:07:00 AMP \\
\hline
\end{tabular}


Table B.2: Daily Returns of Equity Indices

\begin{tabular}{lccc}
\hline & Release & Nonrelease & All Days \\
\hline SP500 Ex-Financial & & & \\
Mean & -0.03 & 0.03 & 0.02 \\
& $(0.06)$ & $(0.02)$ & $(0.02)$ \\
Std Deviation & 1.32 & 1.12 & 1.14 \\
& $(0.04)$ & $(0.01)$ & $(0.01)$ \\
Observations & 486 & 5,048 & 5,534 \\
\hline SmallCap 600 & & & \\
Mean & 0.03 & 0.03 & 0.03 \\
& $(0.07)$ & $(0.02)$ & $(0.02)$ \\
Std Deviation & 1.58 & 1.39 & 1.41 \\
& $(0.05)$ & $(0.01)$ & $(0.01)$ \\
Observations & 486 & 4,603 & 5,089 \\
\hline Russell 2000 & & & \\
Mean & 0.02 & 0.02 & 0.02 \\
Std Deviation & $(0.08)$ & $(0.02)$ & $(0.02)$ \\
& 1.70 & 1.46 & 1.48 \\
Observations & $(0.05)$ & $(0.01)$ & $(0.01)$ \\
\hline
\end{tabular}

Notes: This table shows descriptive statistics of daily returns of equity indices (S\&P 500 Ex-Financials, S\&P Small Cap 600, and Russell 2000). Returns are computed as daily log differences. Mean and standard deviations are reported in percent. "Release Days" refer to days with earnings releases by financial intermediaries in the sample; "Nonrelease Days" refer to days without earnings releases; "All Days" include both release days and nonrelease days. Standard errors are in parentheses. 
Table B.3: Daily Changes in Bond Option-Adjusted Spreads

\begin{tabular}{lcccc}
\hline & Release & Non-Release & All Days & N Bonds \\
\hline AAA & & & & \\
Mean & -0.07 & 0.03 & 0.02 & 293 \\
& $(0.05)$ & $(0.03)$ & $(0.02)$ & \\
Std Deviation & 5.96 & 10.38 & 10.02 & \\
& $(0.03)$ & $(0.02)$ & $(0.02)$ & \\
\hline CCC & & & & \\
Mean & 1.20 & 1.80 & 1.74 & 3,308 \\
& $(0.29)$ & $(0.10)$ & $(0.09)$ & \\
Std Deviation & 110.09 & 106.81 & 107.17 & \\
& $(0.20)$ & $(0.07)$ & $(0.06)$ & \\
\hline All bonds & & & & \\
Mean & 1.07 & 1.60 & 1.55 & 3,601 \\
& $(0.26)$ & $(0.09)$ & $(0.08)$ & \\
Std Deviation & 104.11 & 100.86 & 101.21 & \\
& $(0.18)$ & $(0.06)$ & $(0.06)$ & \\
\hline
\end{tabular}

Notes: This table shows descriptive statistics of daily changes in option-adjusted spreads for nonfinancial constituent bonds in ICE BofA's AAA and CCC \& Lower indices of U.S. corporate bonds. The mean and standard deviation of daily changes in option-adjusted spreads are reported in basis points. The number of nonfinancial constituent bonds (cusip) in each index is reported. "Release Days" refer to days with earning releases by financial intermediaries in the sample; "Nonrelease Days" to days without earnings releases; "All Days" include both release days and nonrelease days. Standard errors are in parentheses.

Table B.4: Bond Holdings by Intermediary

\begin{tabular}{lcccc}
\hline Financial Intermediary & Mean & SD & Min & Max \\
\hline J.P. Morgan Chase & 9,782 & 31,692 & 0 & 351,996 \\
Goldman Sachs & 3,963 & 14,337 & 0 & 254,385 \\
Ameriprise Financial & 2,486 & 8,389 & 0 & 113,540 \\
Northern Trust & 910 & 4,674 & 0 & 88,840 \\
Wells Fargo & 734 & 2,875 & 0 & 38,253 \\
Citicorp & 624 & 3,029 & 0 & 66,300 \\
Bank of New York Mellon & 588 & 2,647 & 0 & 48,695 \\
Morgan Stanley & 244 & 1,234 & 0 & 28,555 \\
Merrill Lynch & 17 & 276 & 0 & 8,901 \\
U.S. Bancorp & 7 & 55 & 0 & 2,000 \\
Bank of America & 2 & 45 & 0 & 1,580 \\
\hline All & 1,760 & 11,337 & 0 & 351,996 \\
\hline
\end{tabular}

Notes: This table shows descriptive statistics on bond holdings by financial intermediaries. The set of bonds includes bonds rated CCC or lower in ICE issued by firms with at least 10 bonds outstanding. 
Figure B.1: Construction of Financial Shocks

(a) Median Positive Shock (Inside Regular Trading Hours)

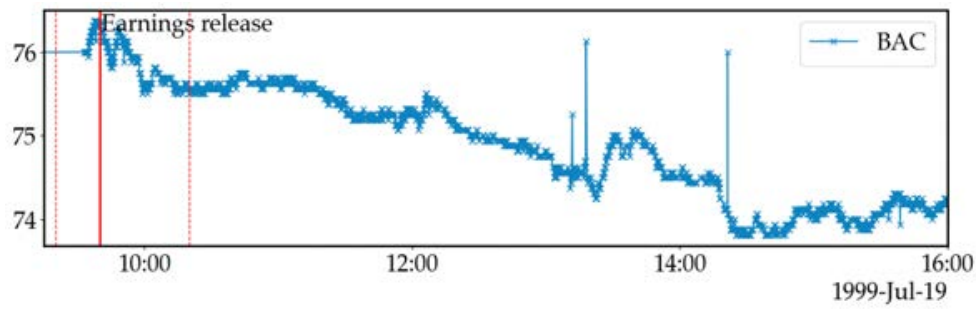

(b) Median Negative Shock (Inside Regular Trading Hours)

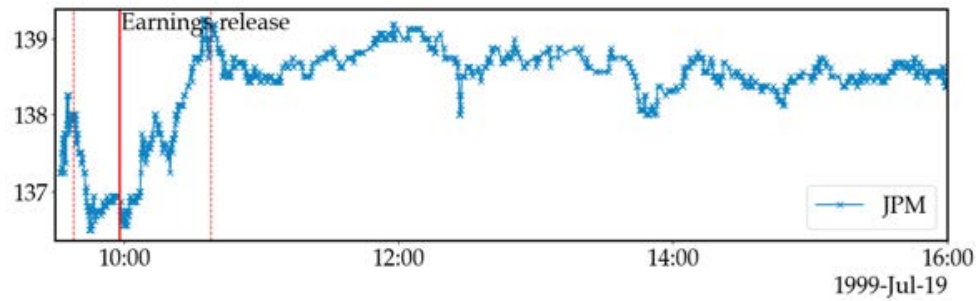

(c) Median Positive Shock (Outside Regular Trading Hours)

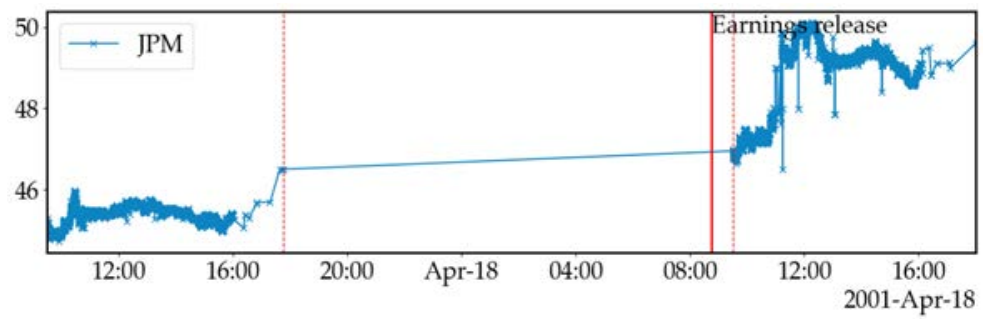

(d) Median Negative Shock (Outside Regular Trading Hours)

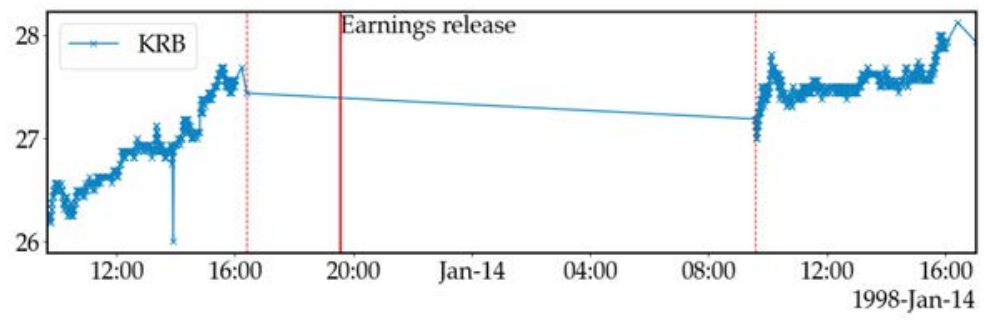


Figure B.2: The Effect of Financial Shocks on the Financial Sector's Net Worth
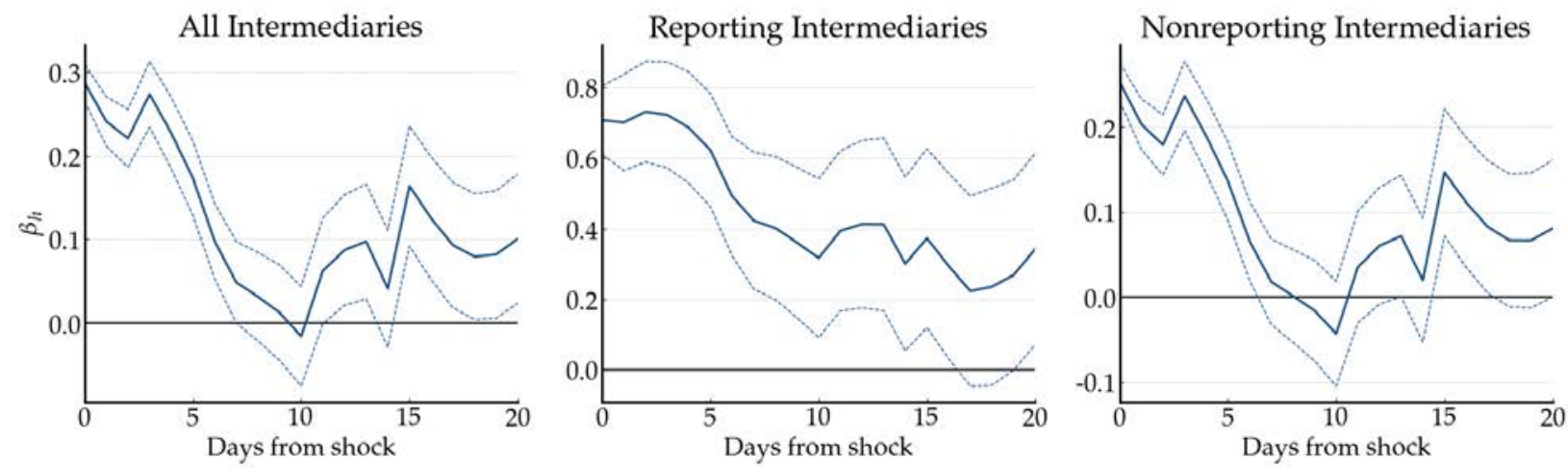

Notes: The figures show the cumulative responses of financial intermediaries' market capitalization to individual unweighted financial shocks. The left panel shows market capitalization responses from all financial intermediaries in our sample in response to a financial shock. The middle panel shows the market capitalization response from the intermediary that reports the earnings underlying the financial shock. The right panel shows the market capitalization response from all remaining nonreporting intermediaries.

Table B.5: Effects of Financial Shocks (Alternative Weighting of S\&P 500 Firms)

\begin{tabular}{lccccc}
\hline & $\begin{array}{c}(1) \\
\text { Equal-weighted }\end{array}$ & $\begin{array}{c}(3) \\
\text { Value-weighted }\end{array}$ & $\begin{array}{c}(5) \\
\text { HF Index }\end{array}$ \\
\hline $\begin{array}{l}\text { Independent variables: } \\
\text { Fin shock (narrow) }\end{array}$ & $\begin{array}{c}0.291^{* *} \\
(0.140)\end{array}$ & $\begin{array}{c}0.292^{* *} \\
(0.147)\end{array}$ & $\begin{array}{c}0.215^{* *} \\
(0.099)\end{array}$ & $\begin{array}{c}0.223^{* *} \\
(0.104)\end{array}$ & $\begin{array}{c}0.235^{* *} \\
(0.094)\end{array}$ \\
& & & & & \\
\hline$R^{2}$ & 0.014 & 0.015 & 0.006 & 0.007 & 0.026 \\
Observations & 104,167 & 104,167 & 102,058 & 102,058 & 341 \\
Macro controls & no & yes & no & yes & yes \\
Cusip FE & yes & yes & yes & yes & no \\
Double-clustered SE & yes & yes & yes & yes & no \\
\hline
\end{tabular}

Notes: This table reports estimates from the event-time regression $\Delta y_{j t}=\alpha_{j}+\beta \varepsilon_{t}^{\mathrm{F}}+u_{j t}$ using different weighting for the dependent variable $\Delta y_{j t} . \alpha_{j}$ is a cusip fixed effect and $\varepsilon_{t}^{\mathrm{F}}$ is the narrow HF shock. Baseline columns 1 and 2 (same as in Table 3) estimate the effect of narrow HF financial shocks on equal-weighted log price changes in S\&P 500 nonfinancial constituents' stocks. Columns 3 and 4 estimate the effect of narrow HF financial shocks on the log price changes in S\&P 500 nonfinancial constituents' stocks weighted by their market values at the beginning of the quarter. Standard errors in columns 1 through 4 are two-way clustered at shock and cusip level. Column 5 replaces the cusip fixed effect with a constant to estimate the effect of financial shocks on the broad S\&P 500 index at high frequency, measured through the exchange-traded fund SPDR. Macro controls include output, employment, and an indicator variable for recession. ${ }^{*}(p<0.10)$, ** $(p<0.05),{ }^{* * *}(p<0.01)$. 
Table B.6: Financial Shocks vs. Placebo Dow Jones Shocks

(a) Financial Shocks

\begin{tabular}{lcccc}
\hline & SP500 Ex-Fin & SmallCap & Russell & Obs \\
\hline Narrow & $0.924^{* * *}$ & $1.348^{* * *}$ & $1.453^{* * *}$ & 272 \\
& $(0.241)$ & $(0.296)$ & $(0.313)$ & \\
Macro controls & $0.908^{* * *}$ & $1.276^{* * *}$ & $1.381^{* * *}$ & 272 \\
& $(0.243)$ & $(0.299)$ & $(0.316)$ & \\
Broad & $0.720^{* * *}$ & $1.085^{* * *}$ & $1.124^{* * *}$ & 486 \\
& $(0.179)$ & $(0.213)$ & $(0.229)$ & \\
\hline
\end{tabular}

(b) Placebo Dow Jones Nonfinancial Shocks

\begin{tabular}{lcccc}
\hline & SP500 & SmallCap & Russell & Obs \\
\hline Narrow & -0.205 & $-0.557^{*}$ & -0.513 & 546 \\
\multirow{3}{*}{ Macro controls } & $(0.272)$ & $(0.330)$ & $(0.346)$ & \\
& -0.158 & -0.506 & -0.462 & 546 \\
Broad & $(0.272)$ & $(0.329)$ & $(0.345)$ & \\
& 0.334 & 0.064 & 0.135 & 877 \\
& $(0.220)$ & $(0.256)$ & $(0.268)$ & \\
\hline
\end{tabular}

Notes: Results from estimating $\Delta \log y_{t}=\alpha+\beta \varepsilon_{t}+u_{t}$, where $\Delta \log y_{t}$ is the daily log change in one of the following indices: S\&P 500 Ex-Financial, S\&P SamllCap 600, or Russell 2000. Panel (a) shows the estimates for $\beta$ using HF financial shocks, described in the main text. Panel (b) shows placebo tests with HF shocks generated with nonfinancial firms in Dow Jones. Shock construction and regression specifications follow those for financial shocks. Firms are 3M, Alco, Philip Morris, Apple, AT\&T, Bethlehem Steel, Boeing, Caterpillar, Chevron, Cisco, Coca-Cola, Dow, Dupont, Eastman Kodak, Exxon, FW Woolworth, General Electric, General Motors, Goodyear, Hewlett-Packard, Home Depot, Intel, IBM, International Paper, Johnson \& Johnson, Kraft, McDonald's, Merck, Microsoft, Nike, Pfizer, Procter \& Gamble, Sears, Texaco, Union Carbide, United Technologies, UnitedHealth, Verizon, Visa, Walgreens, Walmart, Walt Disney, and Westinghouse. * $(p<$ $0.10),{ }^{* *}(p<0.05),{ }^{* * *}(p<0.01)$. 
Table B.7: Effects of Financial Shocks (Broad Measure)

\begin{tabular}{lccccc}
\hline & $(1)$ & $(2)$ & $(3)$ & $(4)$ & $(5)$ \\
& Equal-weighted & Value-weighted & HF Index \\
\hline $\begin{array}{l}\text { Independent variables: } \\
\text { Fin shock (broad) }\end{array}$ & $\begin{array}{c}0.498^{* * *} \\
(0.116)\end{array}$ & $\begin{array}{c}0.514^{* * *} \\
(0.125)\end{array}$ & $\begin{array}{c}0.479^{* * *} \\
(0.109)\end{array}$ & $\begin{array}{c}0.501^{* * *} \\
(0.117)\end{array}$ & $\begin{array}{c}0.535^{* * *} \\
(0.080)\end{array}$ \\
\hline$R^{2}$ & 0.016 & 0.021 & 0.004 & 0.005 & 0.059 \\
Observations & 256,717 & 256,717 & 252,285 & 252,285 & 849 \\
Macro controls & no & yes & no & yes & yes \\
Cusip FE & yes & yes & yes & yes & no \\
Double-clustered SE & yes & yes & yes & yes & no \\
\hline
\end{tabular}

Notes: This table reports estimates from the event-time regression $\Delta y_{j t}=\alpha_{j}+\beta \varepsilon_{t}^{\mathrm{F}}+u_{j t}$ using the broad measure of financial shocks, $\varepsilon_{t}^{\mathrm{F}}$, which includes earnings announced outside of trading hours, described in Section 3. Columns 1 and 2 estimate the effect of broad HF financial shock on equal-weighted log price changes of S\&P 500 nonfinancial constituents stocks. Columns 3 and 4 estimate the effect of broad HF financial shocks on the log price changes in S\&P 500 nonfinancial constituents' stocks weighted by their market values at the beginning of the quarter. Standard errors in columns 1 through 4 are two-way clustered at shock and cusip level. Column 5 replaces the cusip fixed effect with a constant to estimate the effect of financial shocks on the broad S\&P 500 index at high frequency, measured through the exchange-traded fund SPDR. Macro controls include output, employment, and an indicator variable for recession. ${ }^{*}(p<0.10)$, ** $(p<0.05), * * *(p<0.01)$.

Figure B.3: Effects of Financial Shocks on Corporate Bond Spreads

(a) AAA spreads

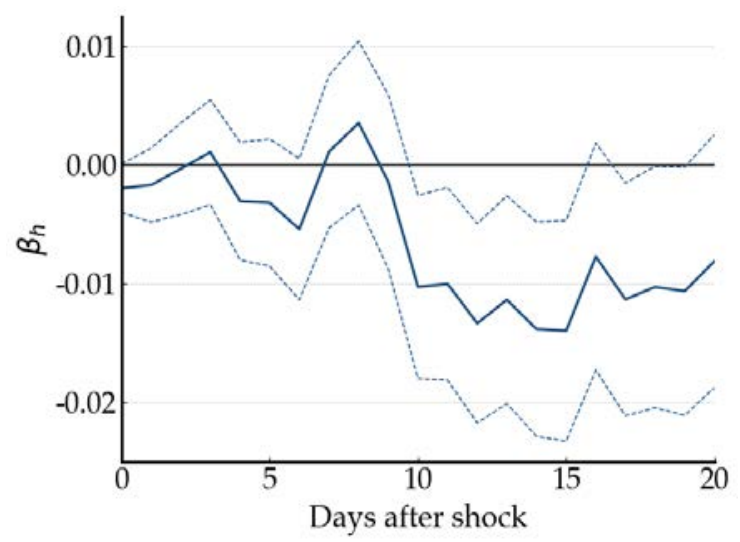

(b) CCC spreads

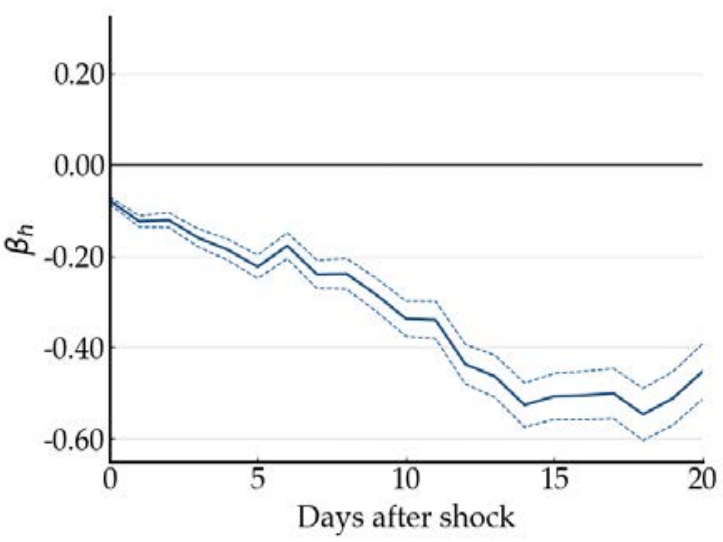

Notes: The figures show the estimated cumulative responses, $\beta_{h r}$, of the bond spreads of rating $r$ to HF shocks at horizon $h$ from estimating pooled local projections $\Delta_{h} z_{k t}=a_{h r}+\alpha_{q}+\beta_{h r} \varepsilon_{t}^{\mathrm{F}}+u_{k r t}$, where $\varepsilon^{\mathrm{F}}$ is the narrow measure of financial shocks, $z_{k r t}$ is the spread of bond $k$ of rating $r$ in period $t$ of an earnings announcement, and $\alpha_{q}$ is a quarter fixed effect. The left panel reports the responses of nonfinancial constituent bonds in the AAA index and the right panel reports the responses of nonfinancial constituent bonds in the CCC or Lower index. Dotted lines represent 90\% confidence intervals. 
Figure B.4: Placebo Tests: Financial Shocks on Nonevent Days
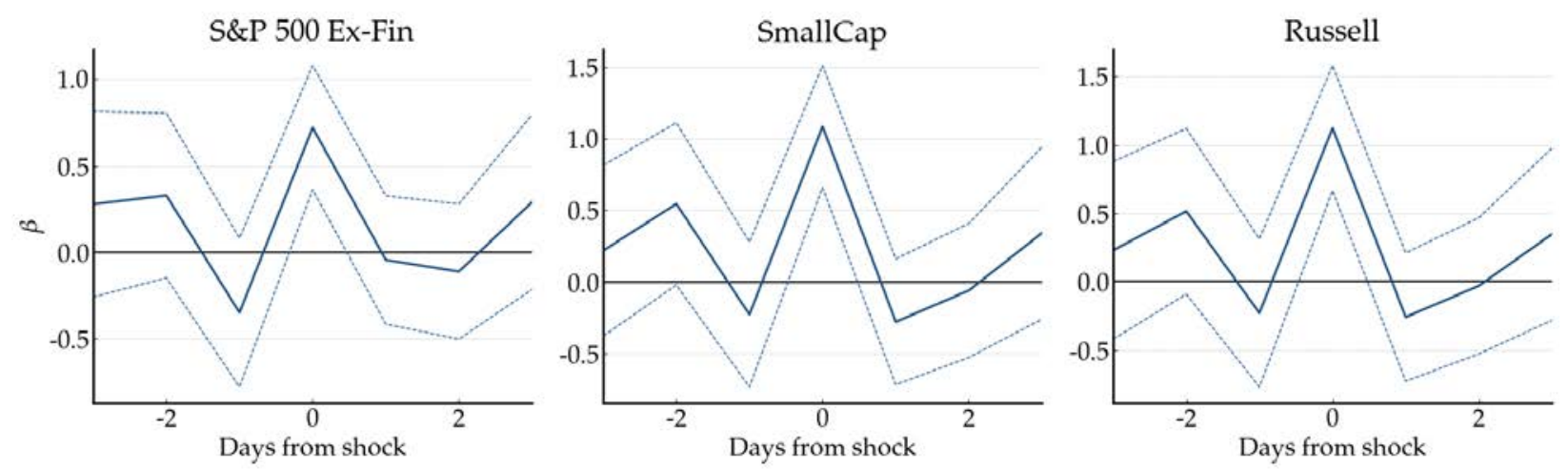

Notes: The figures show placebo tests with nonevent days. Specifications take the form $\Delta \log y_{t+j}=c+$ $\beta \varepsilon_{t}+u_{t}$. Changes in dependent equity indices are constructed using alternative dates $j=-3, \cdots, 3$ around the event date, with $j=0$ corresponding to the event date of earnings releases.

Table B.8: Effects of HF Placebo Shocks with S\&P 500 Nonfinancial Firms

\begin{tabular}{llc}
\hline Dependent Variables & Placebo Sectors & $\begin{array}{c}\text { Effects of } \\
\text { Placebo Shocks }\end{array}$ \\
\hline SP500 Ex-Energy Index & Energy & -0.729 \\
SP500 Ex-Materials Index & Materials & $(0.617)$ \\
& & -1.261 \\
SP500 Ex-Industrials Index & Industrials & $(0.975)$ \\
SP500 Ex-Consumer Discretionary Index & Consumer Discretionary & 0.526 \\
SP500 Ex-Consumer Staples Index & Consumer Staples & $(1.164)$ \\
& & 0.410 \\
SP500 Ex-Healthcare Index & Healthcare & $0.672)$ \\
SP500 Ex-Information Technology Index & Information Technology & 0.186 \\
& & $1.530)$ \\
SP500 Ex-Communication Services Index & Communication Services & $0.871)$ \\
& & 0.371 \\
SP500 Ex-Utilities Index & Utilities & $(1.391)$ \\
SP500 Ex-Real Estate Index & & -1.536 \\
& Real Estate & $(1.289)$ \\
& & 1.995 \\
& & $(1.620)$ \\
\hline
\end{tabular}

Notes: This table reports the effects of placebo HF shocks. For each nonfinancial sector $s$ of the S\&P 500, the placebo HF shock $\varepsilon_{t}^{s}$ is constructed following the procedure for the narrow measure of HF financial shocks described in Section 3. The specification estimated is $\Delta \log y_{t}^{-s}=\alpha+\beta \varepsilon_{t}^{s}+u_{s t}$ for each sector $s \in\left\{\right.$ energy, materials, information technology, ...\}, where $\varepsilon_{t}^{s}$ is the placebo HF shock and $y_{t}^{-s}$ is the equity index that excludes the placebo shock sector. Standard errors are reported in parentheses. ${ }^{*}(p<0.10)$, ** $(p<0.05), * * *(p<0.01)$. 
Table B.9: Comparison of Event-time and Heteroskedasticity-based Identification

\begin{tabular}{|c|c|c|c|c|c|}
\hline Fin Shock & Freq & Dependent Variable & Freq & OLS & $\begin{array}{l}\text { Heteroske- } \\
\text { dasticity }\end{array}$ \\
\hline reporting intermediaries & $60-\min$ & $\begin{array}{l}\text { SP500 nonfin constituents } \\
\text { (equal weighted) }\end{array}$ & $60-\min$ & $\begin{array}{c}0.291^{* *} \\
(0.140)\end{array}$ & $\begin{array}{l}- \\
-\end{array}$ \\
\hline all intermediaries & 60-min & $\begin{array}{l}\text { SP500 nonfin constituents } \\
\text { (equal weighted) }\end{array}$ & $60-\min$ & $\begin{array}{c}0.183^{* * *} \\
(0.061)\end{array}$ & $\begin{array}{c}0.408^{* * * *} \\
(0.027)\end{array}$ \\
\hline all intermediaries & $60-\min$ & $\begin{array}{l}\text { SP500 nonfin constituents } \\
\text { (value weighted) }\end{array}$ & 60-min & $\begin{array}{c}0.150^{* * *} \\
(0.051)\end{array}$ & $\begin{array}{c}0.360^{* * *} \\
(0.028)\end{array}$ \\
\hline all intermediaries & 60-min & SP500 index ETF & $60-\min$ & $\begin{array}{c}0.134^{* * *} \\
(0.028)\end{array}$ & $\begin{array}{c}0.370^{* * *} \\
(0.027)\end{array}$ \\
\hline all intermediaries & 60-min & SP500 nonfin index & daily & $\begin{array}{c}0.538^{* * *} \\
(0.090)\end{array}$ & $\begin{array}{l}- \\
-\end{array}$ \\
\hline all intermediaries & daily & SP500 nonfin index & daily & $\begin{array}{l}- \\
-\end{array}$ & $\begin{array}{c}0.400^{* * *} \\
(0.024)\end{array}$ \\
\hline
\end{tabular}

Notes: This table compares estimators for the effects of financial shocks from event-time and heteroskedasticity-based identification for various combinations of frequency, definitions of financial shocks, and weighting of the dependent variables. A specification that is infeasible for an identification strategy is omitted. * $(p<0.10),{ }^{* *}(p<0.05),{ }^{* * *}(p<0.01)$. 


\section{Content of HF Financial Shocks}

In this section, we provide supportive evidence on the financial content of HF shocks.

\section{C.1. Unexpected earnings and financial shocks}

Figure C.1 studies the relationship between surprise earnings and financial shocks. We measure surprise earnings using the standardized unexpected earnings following the post-earningsannouncement-drift literature (see, for example, Chordia and Shivakumar, 2006), defined as the difference between the reported earnings per share and the consensus forecast, normalized by the standard error of analysts' forecast errors. We obtain data on reported earnings and analysts' forecasts from IBES.

For each earnings announcement, we compare the unexpected earnings of financial institutions with their HF stock price movements used to construct the HF shocks. Figure C.1 shows that stock price movements from financial institutions tend to be positively associated with their surprise earnings, which suggests that financial shocks encode the information on earnings released in the announcements.

Figure C.1: Earnings Surprises and Financial Shocks

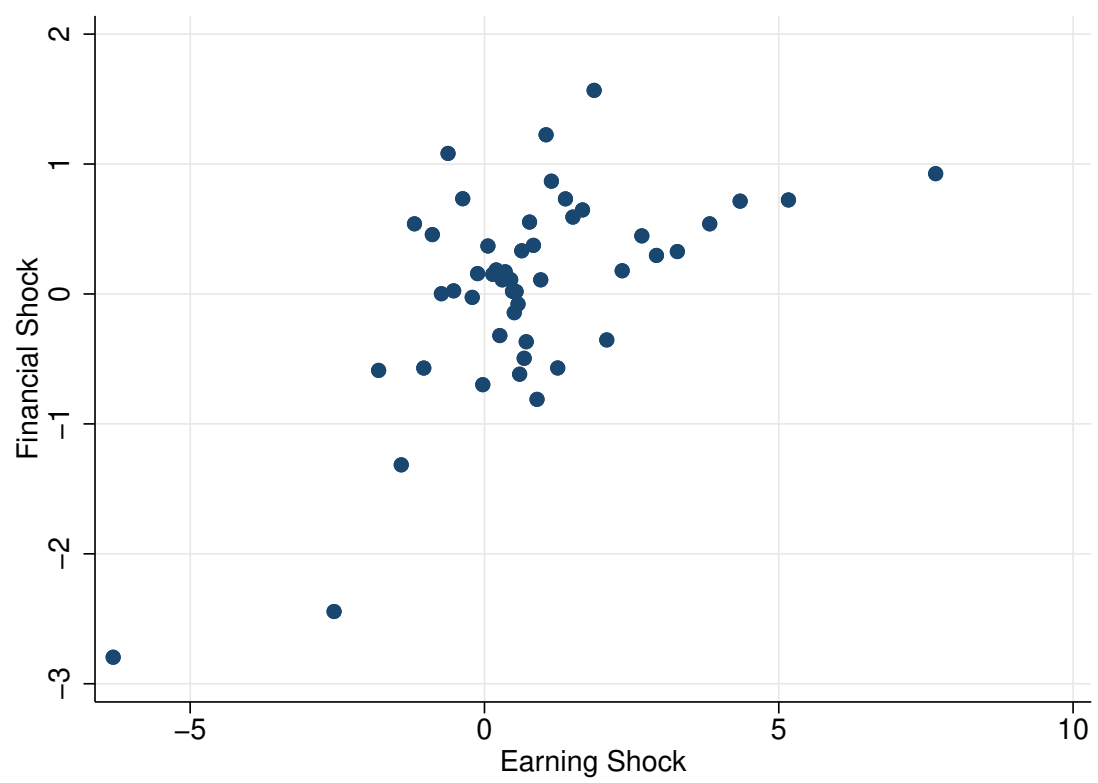

Notes: This figure shows a binned scatter plot between financial shocks and earnings surprises with 50 bins. Financial shocks are unweighted and constructed as described in the main text. Earnings surprises are measured as standardized unexpected earnings, defined in the text. 


\section{C.2. Textual analysis}

We conduct three textual analyses to provide evidence that market participants interpret the earnings as driven by idiosyncratic factors related to intermediaries and not macroeconomic factors. Our textual sample is based on the Wall Street Journal's (WSJ) coverage of intermediaries' earnings announcements. We search through Factiva, a news database, and the WSJ's online archive for articles corresponding to the financial earnings announcements included in our sample and collect a textual sample of 807 articles. We remove metadata, such as dates of articles, names of reporters, and alt text of pictures, to form the corpus for analysis.

\section{C.2.1. Sentiment analysis}

The first exercise asks whether HF shocks capture the market sentiment of an intermediary's earnings outcome. To answer this question, we measure textual sentiment in the news covering an intermediary's earnings result and analyze the relationship between textual sentiment and the earnings result and stock price movements.

The sentiment of the WSJ's reporting on an earnings release is measured using the Loughran and McDonald (2011) dictionary updated in 2018, which categorizes words into four sentiments (positive, negative, uncertain, or of no particular sentiment). Compared with other dictionaries such as the Harvard IV-4 dictionary and Lasswell value dictionary, Loughran and McDonald (2011) categorize sentiment specific to an economic context and is widely adopted in macro and financial applications (see, for example, Hassan, Schwedeler, Schreger and Tahoun, 2021). We measure positive (negative) sentiment as the percentage of positive (negative) words out of total unique words in a news piece. For robustness, we construct an additional measure of positive sentiment as the percentage of positive minus negative words out of total unique words.

Table C.1a reports the relationship between the surprise component of earnings and the news sentiment of the underlying earnings releases. It shows that better-than-expected earnings are associated with more positive coverage, which suggests that market sentiment as measured through WSJ coverage primarily focuses on the earnings outcome. Table C.1b reports the relationship between unweighted HF financial shocks and news sentiment. It shows that HF shocks capture the market sentiment, as measured through WSJ coverage. More positive news coverage is associated with more positive movements in the intermediary's stock prices within a narrow window, and more negative news coverage is associated with more negative movements in the stock prices. 


\section{C.2.2. Topic modeling}

The second exercise asks whether market participants attribute earnings outcomes to intermediaries' idiosyncratic performance or macroeconomic factors. To answer this question, we use a latent Dirichlet allocation (LDA) model (Blei, Ng and Jordan, 2003) to detect topics discussed in the WSJ's coverage of the earnings release.

LDA is a Bayesian factor model aimed at reducing high-dimensional text into a few "topics" or factors. Documents are represented as random mixtures of latent topics. Given $D$ documents that constitute a corpus of text with $V$ unique vocabulary and $K$ topics, each topic $k$ is represented by a

distribution over the vocabulary $\beta_{k} \in \Delta^{V-1}$, and each document $d$ is represented by a distribution over the topics $\theta_{d}^{k}$. LDA assumes a generative process for each document and places Dirichlet priors on $\beta_{k}$ and $\theta_{d}$. The limited inputs imposed by researchers and the high interpretability of its output make it a valuable tool for detecting themes in economic text (Hansen, McMahon and Prat, 2018; Larsen and Thorsrud, 2019; Bybee, Kelly, Manela and Xiu, 2021).

We preprocess the text to reduce the vocabulary to a set of terms that are most likely to answer the question: Do market participants attribute earnings outcomes to intermediary-specific factors or macroeconomic factors? To that end, we first transform individual bank names into a single token (for example, JP Morgan Chase and Goldman are both converted to the token bankname). Next, we remove numeric values, stop words (such as a and the), capitalization, and tokens with fewer than 3 characters, appearing less than 5 times, or in more than $80 \%$ of the documents, and lemmatize the tokens (for example, increases and increase are both lemmatized to increase). The advantage of lemmatization over stemming is that it produces more human-friendly output. Finally, we add to the vocabulary phrases (bigrams) whose frequency is higher than 10.

We estimate the LDA model using the online variational Bayes algorithm developed by Hoffman, Bach and Blei (2010) and assign symmetric Dirichlet priors. An important parameter of the model is the number of topics $K$. We choose $K$ to maximize the topic coherence score (Röder, Both and Hinneburg, 2015), so that the topics produced by the model are most likely to be interpretable. Figure C.2b shows that $K=3$ is the optimal choice of topic numbers under this criterion.

Figure C.2a reports the topics detected by the LDA model. All three topics center around an intermediary's idiosyncratic performance. The first two topics focus on loans and mortgages, the core business areas of commercial banks, and the last topic focuses on investment banking and trading. None of the topics, however, relate to the macroeconomy, which indicates that the WSJ attributes earnings outcomes to factors specific to intermediaries rather than macroeconomic 
fluctuations.

\section{C.2.3. Narratives}

The last textual analysis provides further context for the narratives around earnings. We focus on the coverage of individual banks and study what market participants perceive as the causes and consequences of the earnings. We focus on three banks with the most WSJ coverage (J.P. Morgan, Goldman Sachs, and Wells Fargo) and analyze the causal stories constructed in the coverage of each banks with the algorithm based on relatio developed in Ash, Gauthier and Widmer (2021).

The unit of analysis is a sentence. The first step in the analysis is to reduce the dimensionality by grouping terms that tend to convey the same meaning. As part of the dimensionality reduction, we perform text preprocessing by converting variants of an intermediary's name to its stock ticker (for example, Goldman, Goldman Sachs and Goldman Sachs Group are all converted into the token GS). We also convert dollar amounts (such as $\$ 200$ million) and percentages (such as 2.5\%) into single tokens of dollaramount and percentamount, respectively. After the preprocessing, we tag named identities (such as person names, organizations) and use the K-means algorithm to cluster together terms with the same sentence embeddings. The goal of this step is to transform terms with similar meanings, like earnings and earnings outcome, into a single token. In the estimation, we specify the number of named entities and cluster to both be 50 .

The second and central step of the analysis is the semantic role labeling of a sentence, which labels the who is doing what to whom of a sentence. It labels the agent ("who"), the verb ("what"), and the object ("whom"). With this step, we can study the causes market participants attribute intermediaries' earnings results to.

Figure C.3 plots the top 30 narratives for each intermediary. On close inspection of the coverage of the three intermediaries, narratives around their earnings announcement fall into three categories. The first summarizes the earnings result (e.g., "bank report result," "bank highlight strong"). The second relates earnings to market expectations (e.g., "result surpass expectation," "thomson poll analyst"). The last analyzes the drivers of earnings (e.g., "attractive business risk

capability hold revenue," "bank report organic growth," "bank cut loan," "bank dro credit loss provision"). Of the narratives in the last category which analyze the causes of earnings, none revolves around macroeconomic factors and all discuss intermediary-specific factors. 
Table C.1: News Sentiment, Earnings Surprises, and Financial Shocks

(a) News Sentiment and Earnings

\begin{tabular}{lccc}
\hline & $(1)$ & $(2)$ & $(3)$ \\
& \multicolumn{3}{c}{ Earnings Surprises } \\
\hline \% Positive & $0.862^{* * *}$ & & \\
& $(0.148)$ & & \\
$\%$ Negative & & $-0.484^{* * *}$ & \\
$\%$ (Positive - Negative) & & $0.065)$ & $0.471^{* * *}$ \\
& & & $(0.051)$ \\
\hline Observations & 529 & 529 & 529 \\
$R^{2}$ & 0.094 & 0.079 & 0.128 \\
\hline
\end{tabular}

(b) News Sentiment and Stock Prices

\begin{tabular}{lccc}
\hline & $(1)$ & $(2)$ & $(3)$ \\
& \multicolumn{3}{c}{ Stock Price Changes } \\
\hline$\%$ Positive & $0.377^{* * *}$ & & \\
\% Negative & $(0.125)$ & & \\
$\%$ (Positive - Negative) & & -0.133 & \\
& & & $0.160^{* *}$ \\
& & & $(0.064)$ \\
\hline Observations & 529 & 529 & 529 \\
$R^{2}$ & 0.015 & 0.005 & 0.012 \\
\hline
\end{tabular}

Notes: Panel (a) reports the relationship between standardized surprise earnings and WSJ textual sentiment. Panel (b) reports the relationship between high-frequency changes in stock prices and WSJ sentiment. Three measures of textual sentiment in WSJ coverage are reported: percentage of unique positive/negative/positive minus negative tokens out of total unique words in an article, respectively. Robust standard errors are in parentheses.

Figure C.2: LDA Topics in Earnings Coverage

(a) LDA Topics
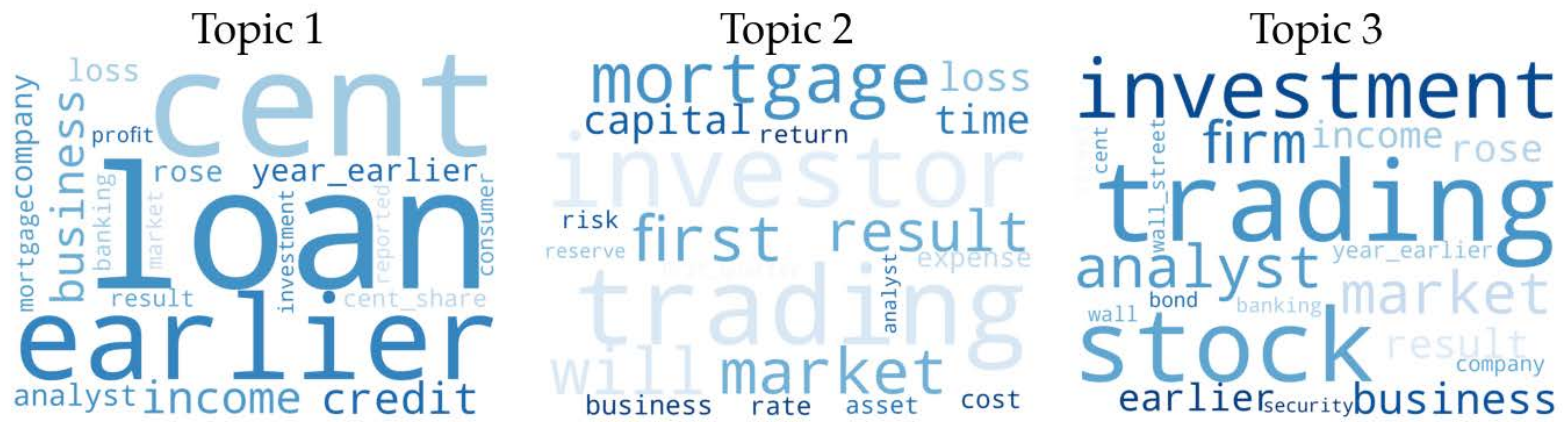

(b) Topic Coherence

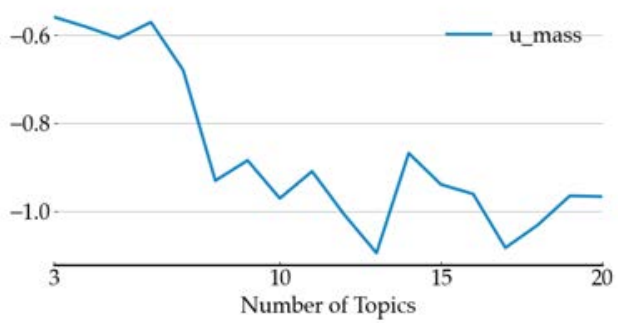

Notes: Panel (a) reports all three topics detected by the LDA model in WSJ articles. A larger font size represents a higher probability of a word or bigram appearing in an article. Panel (b) plots topic coherence measured against the number of topics $K$. Topic coherence is measured by $u_{\text {mass }}=$ $\frac{2}{V(V-1)} \sum_{i=2}^{V} \sum_{j=1}^{i=1} \log \frac{P\left(w_{i}, w_{j}\right)+\varepsilon}{P\left(w_{j}\right)}$, where $\left(w_{i}, w_{j}\right)$ represent a pair of vocabulary. 
Figure C.3: Narratives in Earnings Coverage

(a) J.P. Morgan

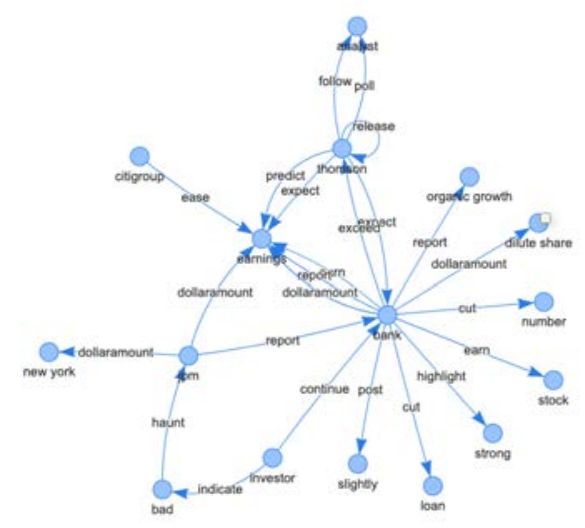

(b) Goldman Sachs

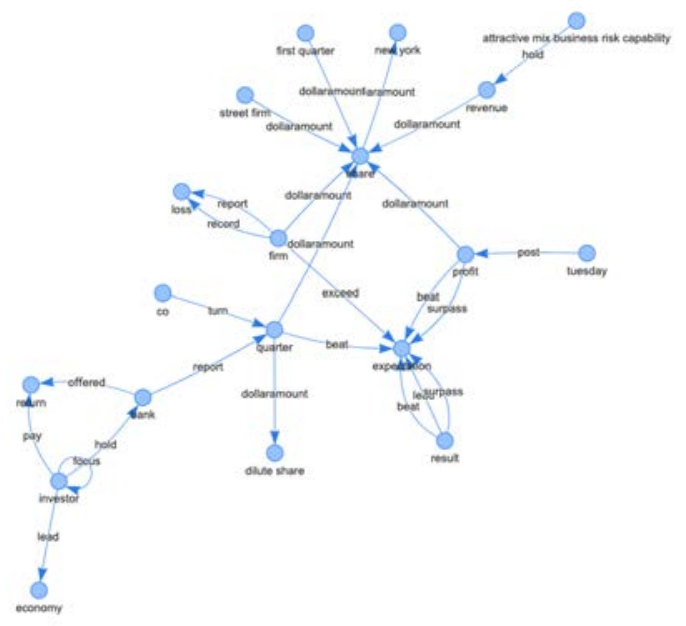

(c) Wells Fargo

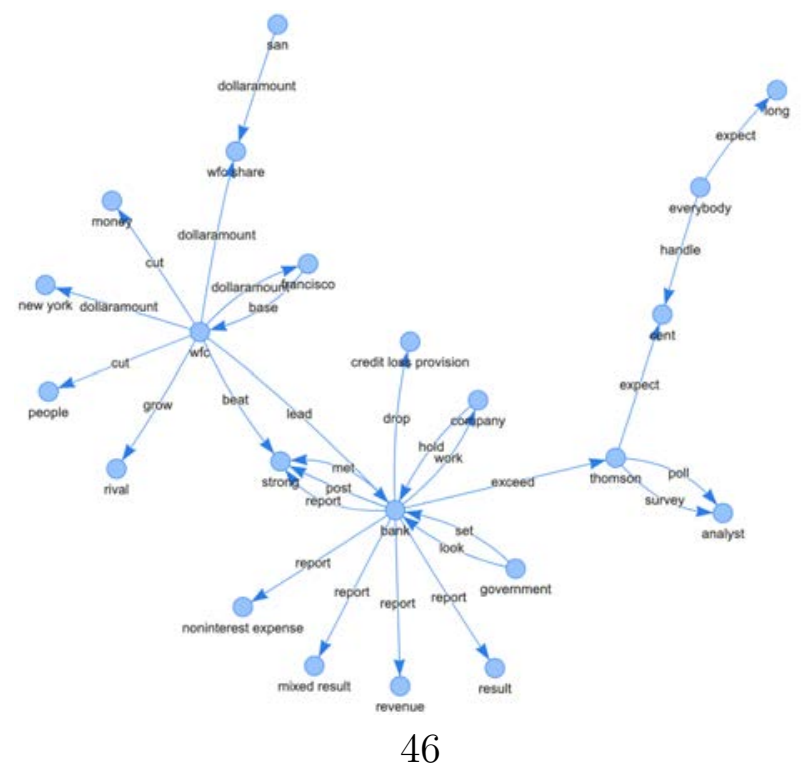




\section{C.3. Predictability of financial shocks}

In this section, we use a state-of-the-art machine-learning model to provide evidence suggesting that HF financial shocks are not predictable using the macroeconomic and financial variables available prior to the shock. We use two sets of predictors. The first macro panel contains a large panel of 126 monthly macroeconomic series constructed by McCracken and Ng (2016) and available through FRED-MD. The second financial panel is of higher daily frequency and includes stock prices of the financial intermediaries in our sample, as well as S\&P 500 and VIX.

Our main forecasting model is random forests (Breiman, 2001), which produce an averaged prediction from a large collection of regression trees. Random forests incorporate nonlinearity and multi-way interactions between predictors, which makes the method useful for macroeconomic and financial forecasting (Gentzkow, Kelly and Taddy, 2019). The random-forest predictor is defined as

$$
\hat{f}_{\mathrm{rf}}^{B}=\frac{1}{B} \sum_{b=1}^{B} T\left(x ; \Theta_{b}\right)
$$

which averages the forecasts of $B$ regression trees $T\left(x ; \Theta_{b}\right)$, where $x$ is the set of predictors and $\Theta_{b}$ characterizes the parameters in the $b$ th tree. ${ }^{12}$

As Gentzkow et al. (2019) argue, the benefits of regression trees from nonlinearity and highorder interactions lessens with high-dimensional predictors, so we first perform variable selection with elastic net (Zou and Hastie, 2005), which is an implementation of soft thresholding regularization that drops uninformative predictors using penalized regressions. The elastic net estimator is defined by

$$
\hat{\beta}_{\mathrm{EN}}=\underset{\beta}{\arg \min }\left\{\frac{1}{2} \sum_{i=1}^{N}\left(y_{i}-\beta_{0}-\sum_{j=1}^{p} x_{i j} \beta_{j}\right)^{2}+\lambda\left(\frac{1}{2}(1-\alpha)\|\beta\|_{l_{2}}^{2}+\alpha\|\beta\|_{l_{1}}\right)\right\},
$$

which minimizes the sum or regression residuals and a penalty term, a weighted average of LASSO and ridge. Following Borup and Schütte (2020), we set $\alpha=0.5$ for an equal weight between LASSO and ridge regressions and tune the penalty parameter $\lambda$ so that the elastic net selects the 20 best predictors.

We then use random forests to form predictions using 48-month rolling windows for macro predictors and quarter rolling windows for financial predictors. To assess forecastability, we compare

\footnotetext{
${ }^{12}$ See Hastie, Tibshirani and Friedman (2009) for a comprehensive exposition of trees and random forests.
} 
Table C.2: Out-of-Sample $R^{2}$ of Predictions of Financial Shocks

\begin{tabular}{lrr}
\hline & Macro & Financial \\
\hline Random Forest & $-15.1 \%$ & $-16.8 \%$ \\
Random Walk Benchmark & & $-5.2 \%$ \\
\hline
\end{tabular}

Notes: This table reports the out-of-sample $R^{2}$ of random-forest forecasts based on a large panel of macroeconomic and financial variables compared against out-of-sample $R^{2}$ of random-walk forecasts based on stock returns one day before the shock. The out-of-sample $R^{2}$ is defined as $R_{\text {oos }}^{2}=1-\frac{\Sigma_{t}\left(y_{t}-\hat{y}_{m, t}\right)^{2}}{\Sigma_{t}\left(y_{t}-\bar{y}_{t}\right)^{2}}$ where $\bar{y}_{t}$ is the rolling-mean forecast computed on a window matching the model-estimation window, and $\hat{y}_{m, t}$ is the forecast from the model. Negative numbers indicate the forecast underperforms the rolling historical mean of the series.

the predictions from random forests against those from a random walk, formed with stock returns 1 day before the financial shock, converted to match the size of the 60-minute shock window. The metric for evaluating forecastability is the out-of-sample $R^{2}$ (Campbell and Thompson, 2008), defined as

$$
R_{\mathrm{oos}}^{2}=1-\frac{\Sigma_{t}\left(y_{t}-\hat{y}_{m, t}\right)^{2}}{\Sigma_{t}\left(y_{t}-\bar{y}_{t}\right)^{2}}
$$

where $\bar{y}_{t}$ is the rolling-mean forecast computed on a window matching the model-estimation window, and $\hat{y}_{m, t}$ is the forecast from the model. $R_{\text {oos }}^{2}$ lies in the range $(-\infty, 1]$, with negative numbers indicating that the model underperforms the historical mean of the series.

Assessments of the forecastability of financial shocks by macroeconomic and financial predictors are shown in Table C.2. Random-forest forecasts with both macro and financial predictors have negative $R_{\mathrm{oos}}^{2}$, which suggests worse performance than historical rolling-mean forecasts. The results also suggest that incorporating panels of macro and financial variables does not help in forecasting HF financial shocks compared with a random walk. 


\section{C.4. Stock-price volatility for financial intermediaries and nonfinancial firms: Event vs. nonevent days}

Table C.3 reports descriptive statistics of the stock price of financial intermediaries and nonfinancial firms in the S\&P 500 during event windows in which intermediaries release earnings and nonevent windows. It show that the volatility of financial intermediaries' stock prices during their earnings announcements increases by substantially more than those of nonfinancial firms during these events, which is consistent with the fact that intermediaries' earnings announcements contain more information about financial intermediaries than about nonfinancial firms.

Table C.3: Summary Statistics for Event and Nonevent Windows

\begin{tabular}{lccccc}
\hline & \multicolumn{2}{c}{ Financial Intermediaries } & & \multicolumn{2}{c}{ Nonfinancial Firms } \\
\cline { 2 - 3 } \cline { 6 - 6 } & Release & Nonrelease & & Release & Nonrelease \\
\hline Mean of weighted $\Delta P$ & 0.12 & 0.05 & & 0.02 & 0.03 \\
& $(0.03)$ & $(0.00)$ & & $(0.02)$ & $(0.00)$ \\
SD of weighted $\Delta P$ & 0.82 & 0.74 & & 0.49 & 0.45 \\
& $(0.02)$ & $(0.00)$ & & $(0.01)$ & $(0.00)$ \\
\hline Observations & 862 & 15,171 & & 862 & 15,171 \\
\hline
\end{tabular}

Notes: This table shows summary statistics for weighted HF stock-price changes for event windows and nonevent windows. Financial intermediaries are the institutions listed in Table 1. Nonfinancial firms are constituents of the S\&P 500 excluding financial firms (naics 52). Standard errors are in parentheses. 


\section{Additional Data and Results for the Transmission Mechanism}

This appendix describes the data sources and construction for Section 5 and presents additional results on the impact of financial shocks by firm exposure and the comparison between HF financial and monetary shocks.

\section{D.1. Data}

In Section 5.2, we study heterogeneous firm responses to financial shocks with quarterly data on firm balance sheet and credit ratings from Compustat. To facilitate comparison with the monetary transmission literature, our sample construction follows that of Ottonello and Winberry (2020). We exclude financial, energy, and utility firms and firm-quarter observations that have negative capital or assets, acquisition larger than $5 \%$ of assets, investment rate in the top or bottom $0.5 \%$ of the distribution, investment spell shorter than 40 quarters, net current assets as a share of total assets higher than 10 or below -10, leverage higher than 10 or negative, quarterly real sales growth above 1 or below -1 , and negative sales or liquidity.

Leverage is defined as the ratio of total debt to total assets. Liquidity is defined as the

ratio of cash and short-term investment to total assets. Leverage and liquidity are demeaned and standardized at firm level so that the units are standard deviations. Credit ratings are measured as S\&P's long-term issue rating of the firm. We use S\&P's definition of investment grade as BBB or better and speculative grade as BB or worse, though our empirical results are robust to other cutoffs.

We include as firm controls sales growth, measured as log differences in sales deflated by the BLS implicit price deflator; size, measured as log total real assets deflated using the BLS implicit price deflator; current assets as a share of total assets; and an indicator variable for fiscal quarter. Sales growth, size, and current-to-total assets are standardized.

We also compare the effect of a financial shock with that of a monetary shock in high frequencies. The monetary shock, as constructed by Gorodnichenko and Weber (2016), is based on changes in Fed funds futures in a 60-minute window around an FOMC announcement

$$
\varepsilon_{t}^{\mathrm{M}}=\frac{D}{D-\tau}\left(f f_{t+\Delta t^{+}}^{0}-f f_{t+\Delta t^{-}}^{0}\right)
$$


where $t$ is the time of the FOMC announouncement; $f f_{t+\Delta t^{+}}^{0}$ and $f f_{t+\Delta t^{-}}^{0}$ are the fed funds futures rate 15 minutes before and 45 minutes after the announcement; $D$ is the number of days in the month of the announcement; and $\tau$ is the date of the announcement. For each FOMC announcement, we compute the log changes in firms' stock prices in the corresponding 60-minute window around the announcement (15 minutes before and 45 minutes after) to use as the dependent variable. We use the sample before the global financial crisis to focus on comparison with the transmission of conventional monetary policy.

\section{D.2. Comparison of financial and monetary shocks}

We now compare the effects of HF financial and monetary shocks. Both the financial and monetary shock are constructed based on a 60-minute window around the event announcement. The dependent variable is the log changes in nonfinancial Compustat firm stock prices, computed in the 60-minute window around the events to match the frequency of the shocks.

For financial shocks, we estimate (6)

$$
\Delta y_{j t}=\alpha_{j}+\alpha_{s q}+\beta_{F} \varepsilon_{t}^{\mathrm{F}}+\gamma_{F} \varepsilon_{t}^{\mathrm{F}} \mathbb{1}_{x_{j t}}+\Gamma^{\prime} Z_{j t}+u_{j t},
$$

where $\Delta y_{j t}$ is the log changes in stock prices in the 60-minute window around a financial shock, $\varepsilon_{t}^{\mathrm{F}}$ is the narrow HF financial shock; $\mathbb{1}_{x_{j t}}$ is an indicator variable for firms with high leverage, investment-grade credit rating, or high liquidity; $\alpha_{j}$ is a firm fixed effect; $\alpha_{s q}$ is a sector-by-quarter fixed effect; and $Z_{j t}$ is a vector of firm controls - the firm characteristic $\mathbb{1}_{x_{j t}}$, previous-quarter sales growth, previous-quarter size, previous-quarter current assets as a share of total assets, and an indicator for fiscal quarter. Standard errors are two-way clustered at firm and shock level.

For monetary shocks, we replace the sector-by-quarter fixed effect with a sector-by-quarter seasonal fixed effect to estimate the average effect of monetary shocks, since there is typically no more than one shock per quarter:

$$
\Delta y_{j t}=\alpha_{j}+a_{s q}+\beta_{M} \varepsilon_{t}^{\mathrm{M}}+\gamma_{M} \varepsilon_{t}^{\mathrm{F}} \mathbb{1}_{x_{j t}}+\Gamma^{\prime} Z_{j t}+u_{j t}
$$

where $\varepsilon_{t}^{\mathrm{M}}$ is the HF monetary shock and the remaining variables are as defined in (6).

Results are reported in Appendix Table D.1. Panel (a) reports the average effect and heterogeneous transmission of monetary shocks that are consistent with previous studies. The semielasticity to monetary shocks at high frequency, of 2.2 , is roughly half the size of the estimate from daily 
frequency (for example, 5.31 in Gorodnichenko and Weber, 2016). Comparison of Panels (a) and (b) shows that different sources of firm heterogeneity matter for the transmission of monetary and financial shocks: Whereas firms with lower leverage and higher credit ratings are more responsive to monetary policy, firms with lower credit ratings and lower liquidity are those most affected by financial shocks. 
Table D.1: Heterogeneous Firm Responses to Financial and Monetary Shocks

(a) Monetary Shocks

\begin{tabular}{|c|c|c|c|c|}
\hline & $\begin{array}{c}(1) \\
\text { Average }\end{array}$ & $\begin{array}{c}(2) \\
\text { Leverage } \\
\text { (High) }\end{array}$ & $\begin{array}{c}(3) \\
\text { Credit Ratings } \\
\text { (Invt Grade) }\end{array}$ & $\begin{array}{l}(4) \\
\text { Liquidity } \\
\text { (Liquid) }\end{array}$ \\
\hline Monetary shock & $\begin{array}{c}2.205^{* * *} \\
(0.670)\end{array}$ & $\begin{array}{c}2.544^{* * *} \\
(0.711)\end{array}$ & $\begin{array}{c}2.919^{* * *} \\
(1.051)\end{array}$ & $\begin{array}{c}2.125^{* * *} \\
(0.635)\end{array}$ \\
\hline Characteristic & & $\begin{array}{c}0.002 \\
(0.011)\end{array}$ & $\begin{array}{l}-0.053 \\
(0.066)\end{array}$ & $\begin{array}{l}-0.010 \\
(0.011)\end{array}$ \\
\hline Characteristic $\times$ Shock & & $\begin{array}{c}-0.699^{* * *} \\
(0.225)\end{array}$ & $\begin{array}{l}1.379^{* *} \\
(0.530)\end{array}$ & $\begin{array}{c}0.160 \\
(0.138)\end{array}$ \\
\hline Adjusted $R^{2}$ & 0.028 & 0.028 & 0.070 & 0.028 \\
\hline Observations & 159,723 & 159,723 & 38,425 & 159,703 \\
\hline Firm controls & no & yes & yes & yes \\
\hline Quarter-sector FE & no & no & no & no \\
\hline Double-clustered SE & yes & yes & yes & yes \\
\hline
\end{tabular}

(b) Financial Shocks

\begin{tabular}{lcccc}
\hline & $\begin{array}{c}(1) \\
\text { Average }\end{array}$ & $\begin{array}{c}(2) \\
\text { Leverage } \\
(\text { High })\end{array}$ & $\begin{array}{c}(3) \\
\text { Credit Ratings } \\
\text { (Invt Grade) }\end{array}$ & $\begin{array}{c}(4) \\
\text { Liquidity } \\
\text { (Liquid) }\end{array}$ \\
\hline Financial shock & $0.264^{* *}$ & $0.252^{* *}$ & $0.330^{* *}$ & $0.283^{* *}$ \\
& $(0.109)$ & $(0.108)$ & $(0.142)$ & $(0.109)$ \\
Characteristic & & 0.005 & -0.019 & $-0.014^{*}$ \\
& & $(0.008)$ & $(0.018)$ & $(0.007)$ \\
Characteristic $\times$ Shock & & 0.024 & $-0.075^{*}$ & $-0.038^{* *}$ \\
& & $(0.018)$ & $(0.043)$ & $(0.015)$ \\
\hline Adjusted $R^{2}$ & 0.023 & 0.023 & 0.039 & 0.023 \\
Observations & 598,572 & 598,572 & 162,267 & 598,530 \\
Firm controls & no & yes & yes & yes \\
Quarter-sector FE & yes & yes & yes & yes \\
Double-clustered SE & yes & yes & yes & yes \\
\hline
\end{tabular}

Notes: This table reports results from estimating

$$
\begin{aligned}
& \Delta y_{j t}=\alpha_{j}+a_{s q}+\beta_{M} \varepsilon_{t}^{\mathrm{M}}+\gamma_{M}\left(\mathbb{1}_{x_{j t}} \varepsilon_{t}^{\mathrm{M}}\right)+\Gamma^{\prime} Z_{j t}+u_{j t} \\
& \Delta y_{j t}=\alpha_{j}+\alpha_{s q}+\beta_{F} \varepsilon_{t}^{\mathrm{F}}+\gamma_{F}\left(\mathbb{1}_{x_{j t}} \varepsilon_{t}^{\mathrm{F}}\right)+\Gamma^{\prime} Z_{j t}+u_{j t}
\end{aligned}
$$

where $\varepsilon_{t}^{\mathrm{M}}$ and $\varepsilon_{t}^{\mathrm{F}}$ denote narrow HF financial and monetary shocks, respectively, $\mathbb{1}_{x_{j t}}$ is an indicator variable for high leverage, investment-grade credit ratings, or high liquidity; and $Z_{j t}$ is a vector of firm controls - the firm characteristic $\mathbb{1}_{x_{j t}}$, lagged sales growth, lagged size, lagged current assets as a share of total assets, and an indicator for fiscal quarter. We normalize the sign of the monetary shock so that a positive shock corresponds to a decrease in the interest rate. The sample period for monetary shocks stops in 2007 to focus on conventional monetary policy. Standard errors are two-way clustered at shock and firm level and reported in parentheses. $*(p<0.10),{ }^{* *}(p<0.05),{ }^{* * *}(p<0.01)$. 